\title{
Light Water Reactor Sustainability Nondestructive Evaluation for Concrete Research and Development Roadmap
}

September 2012

Prepared by

Dwight Clayton

Michael Hileman

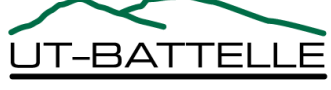




\title{
DOCUMENT AVAILABILITY
}

Reports produced after January 1, 1996, are generally available free via the U.S. Department of Energy (DOE) Information Bridge.

Web site http://www.osti.gov/bridge

Reports produced before January 1, 1996, may be purchased by members of the public from the following source.

\author{
National Technical Information Service \\ 5285 Port Royal Road \\ Springfield, VA 22161 \\ Telephone 703-605-6000 (1-800-553-6847) \\ TDD 703-487-4639 \\ Fax 703-605-6900 \\ E-mail info@ntis.gov \\ Web site http://www.ntis.gov/support/ordernowabout.htm
}

Reports are available to DOE employees, DOE contractors, Energy Technology Data Exchange (ETDE) representatives, and International Nuclear Information System (INIS) representatives from the following source.

Office of Scientific and Technical Information

P.O. Box 62

Oak Ridge, TN 37831

Telephone 865-576-8401

Fax 865-576-5728

E-mail reports@osti.gov

Web site http://www.osti.gov/contact.html

\begin{abstract}
This report was prepared as an account of work sponsored by an agency of the United States Government. Neither the United States Government nor any agency thereof, nor any of their employees, makes any warranty, express or implied, or assumes any legal liability or responsibility for the accuracy, completeness, or usefulness of any information, apparatus, product, or process disclosed, or represents that its use would not infringe privately owned rights. Reference herein to any specific commercial product, process, or service by trade name, trademark, manufacturer, or otherwise, does not necessarily constitute or imply its endorsement, recommendation, or favoring by the United States Government or any agency thereof. The views and opinions of authors expressed herein do not necessarily state or reflect those of the United States Government or any agency thereof.
\end{abstract}




\title{
LIGHT WATER REACTOR SUSTAINABILITY NONDESTRUCTIVE EVALUATION FOR CONCRETE RESEARCH AND DEVELOPMENT ROADMAP
}

\author{
Dwight Clayton \\ Michael Hileman
}

Date Published: September 2012

\author{
Prepared by \\ OAK RIDGE NATIONAL LABORATORY \\ Oak Ridge, Tennessee 37831-6283 \\ managed by \\ UT-BATTELLE, LLC \\ for the \\ U.S. DEPARTMENT OF ENERGY \\ under contract DE-AC05-00OR22725
}





\section{CONTENTS}

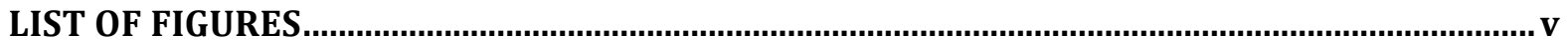

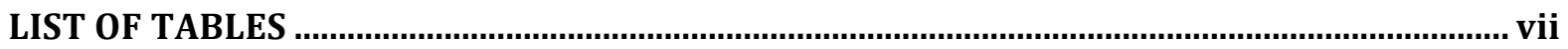

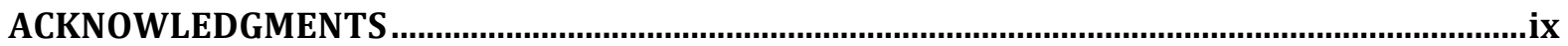

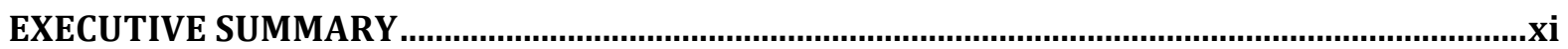

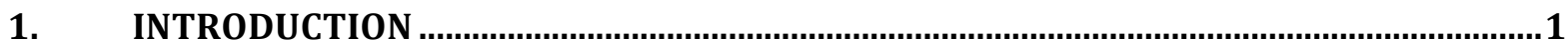

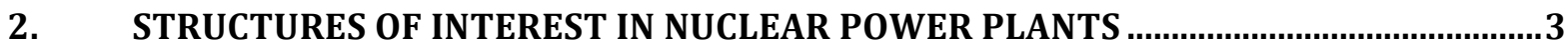

2.1 SAFETY-RELATED STRUCTURES

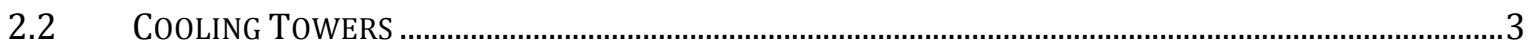

3. GENERAL CHARACTERISTICS OF CONCRETE IN NUCLEAR POWER PLANTS ............... 4

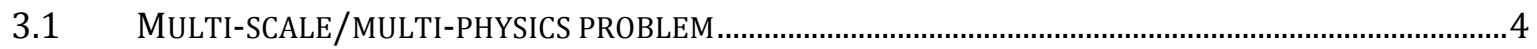

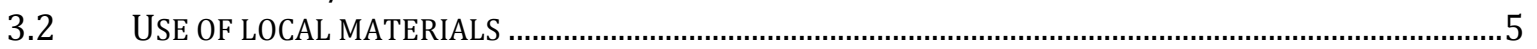

3.3 INTERACTION WITH STEEL

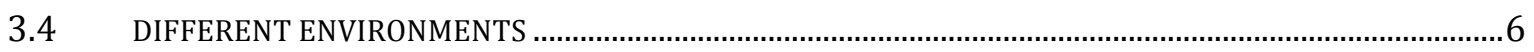

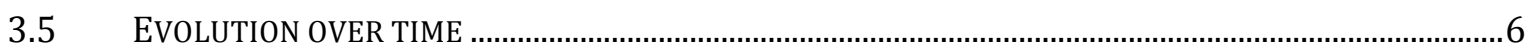

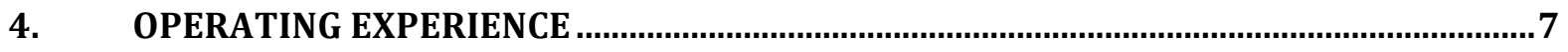

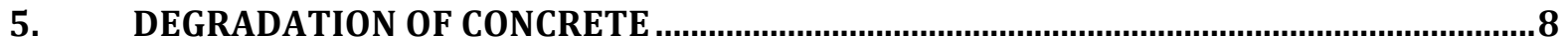

5.1 CONVENTIONAL CLASSIFICATION (KNOWING THAT THE DEGRADATION MODES MAY BE COUPLED).8

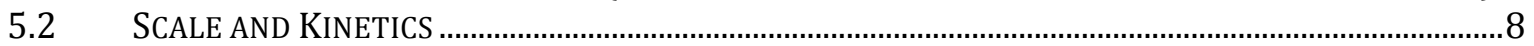

6. IN-SERVICE INSPECTION TESTING

7. REQUIREMENTS FOR AUGMENTED NONDESTRUCTIVE EVALUATION .................... 12

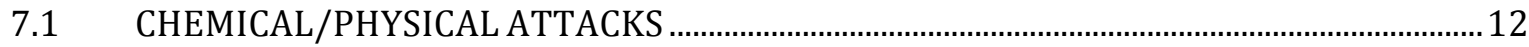

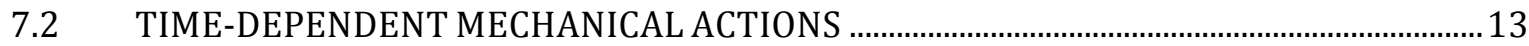

7.3 IMAGING AND DETECTION OF DEFECT IN MASSIVE STRUCTURE .................................... 13

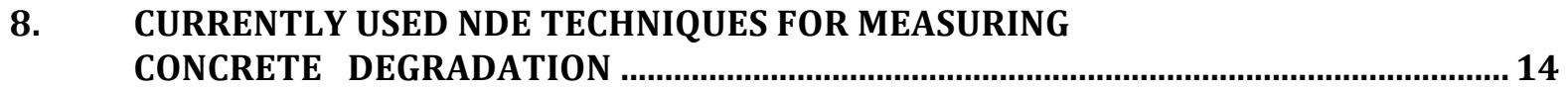

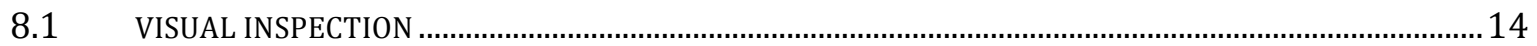

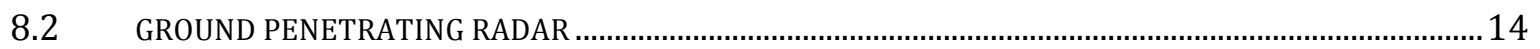

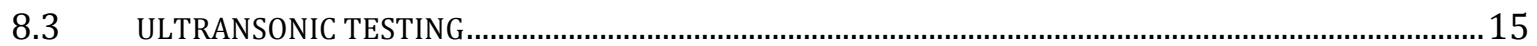

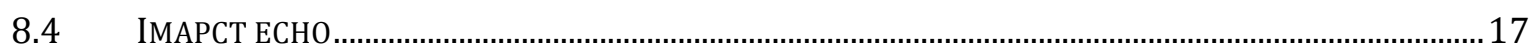

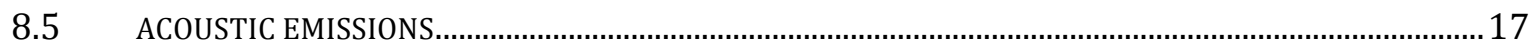

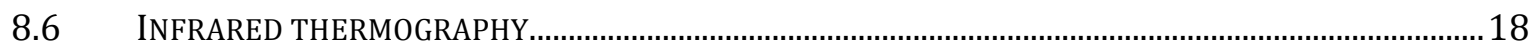

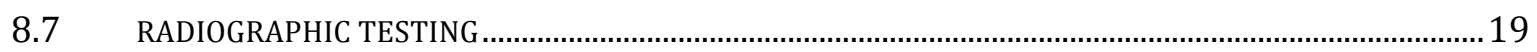

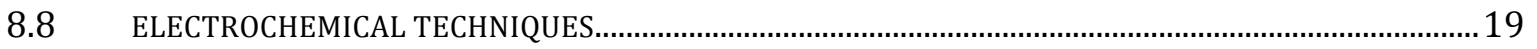

8.9 SUMmARY OF CURRENT NDE CONCRETE MEASUREMENT TECHNIQUES...........................................21

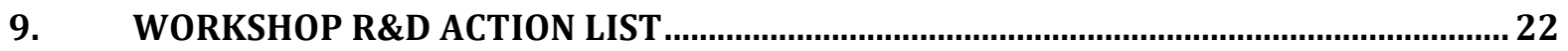

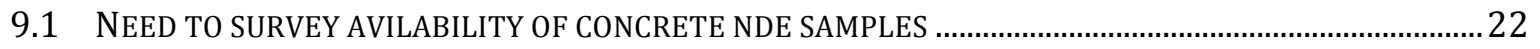

9.2 NEED A TECHNIQUE TO PERFORM VOLUMETRIC IMAGING ON THICK REINFORCED

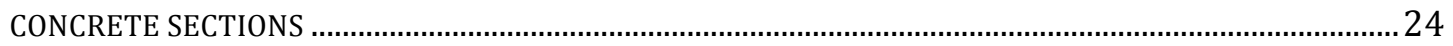

9.3 NEED TECHNIQUES TO DETERMINE PHYSICAL AND CHEMICAL PROPERTIES AS A

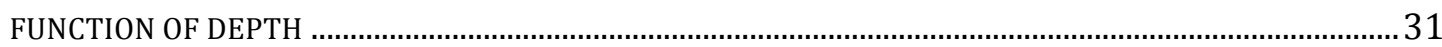


9.4 NEED TECHNIQUES TO DETERMINE INTERFACES BETWEEN CONCRETE AND OTHER MATERIALS.. 32

9.5 NEED TO DEVELOP ACCEPTANCE CRITERIA - MODELING AND VALIDATION .........................................32

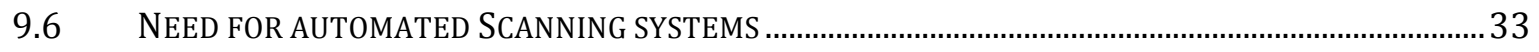

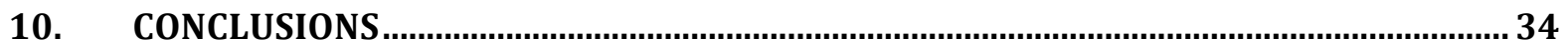

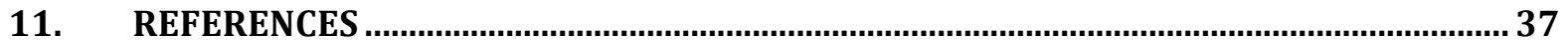

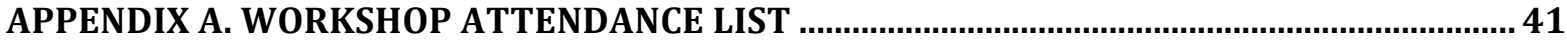

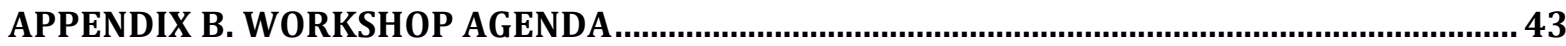

APPENDIX C. WORKSHOP WORKING GROUPS

C-1 WORKING GROUP INTRODUCTION

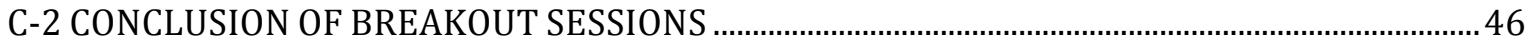




\section{LIST OF FIGURES}

Figure

Page

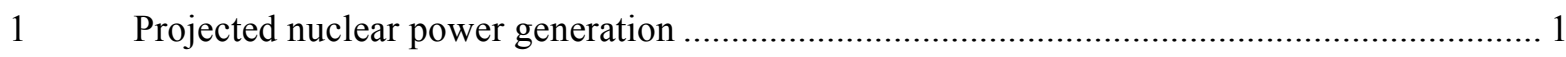

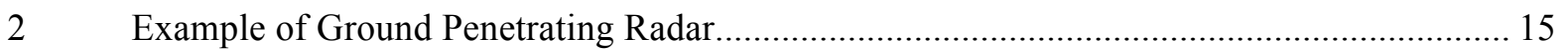

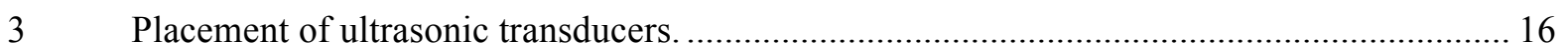

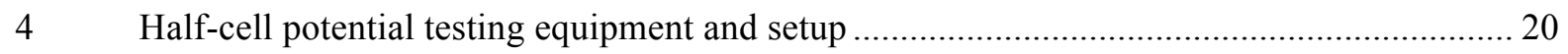

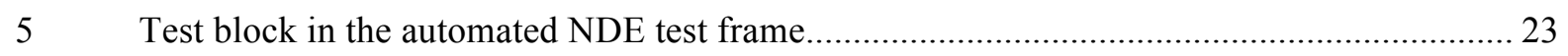

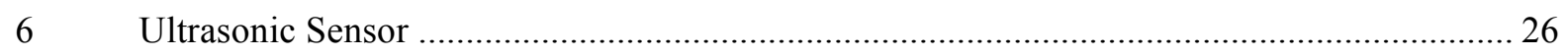

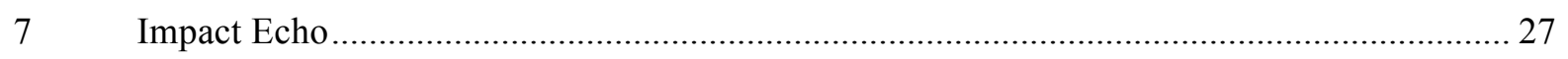

8 Time-consuming scanning using conventional contact sensors ......................................... 28

9 Goal: measurement in continuous motion using a microphone. ......................................... 28

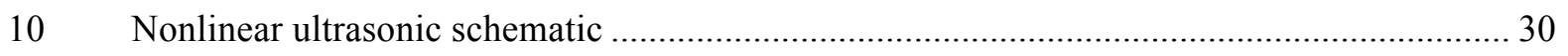

11 Elastic properties from logitudinal and shear ultrasonic waves and density ........................ 31

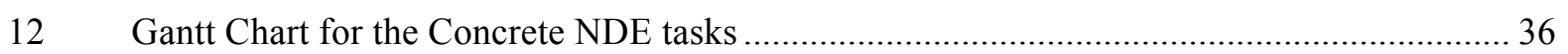





\section{LIST OF TABLES}

\section{Table}

1 Summary of current NDE concrete measurement techniques............................................ 21

2 Sources of radiation for different concrete thicknesses..................................................... 31

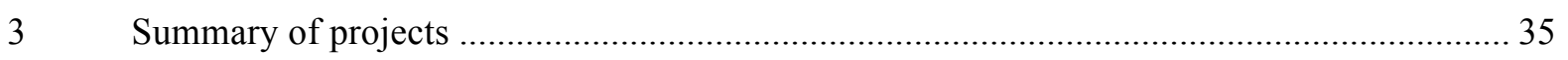

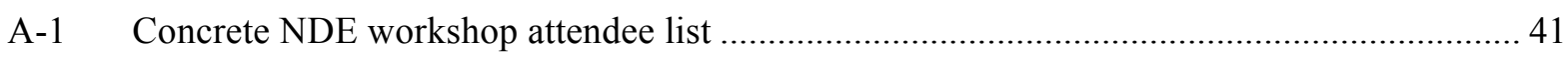

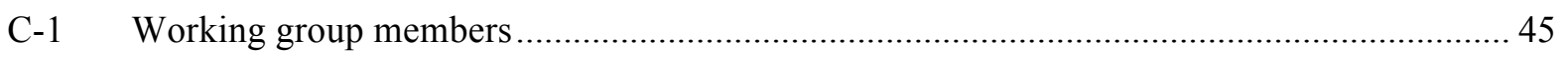

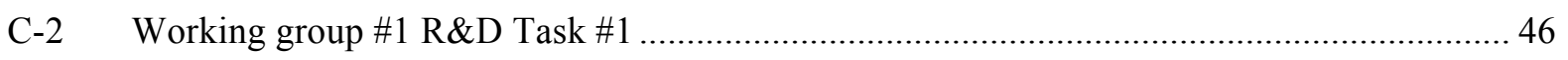

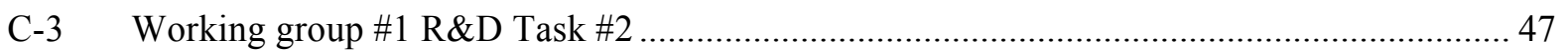

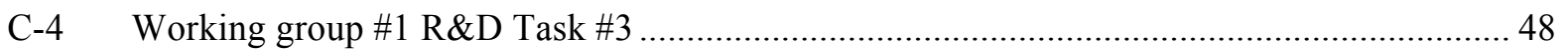

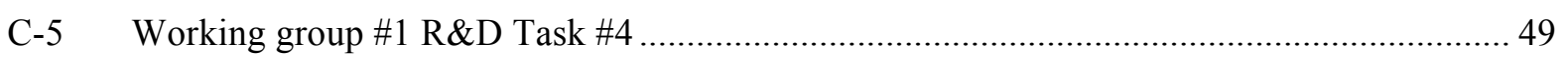

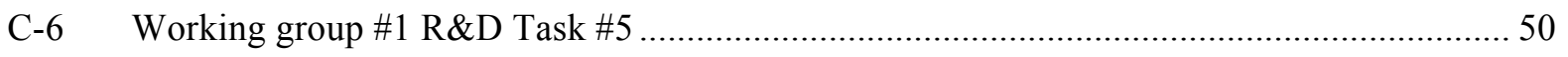

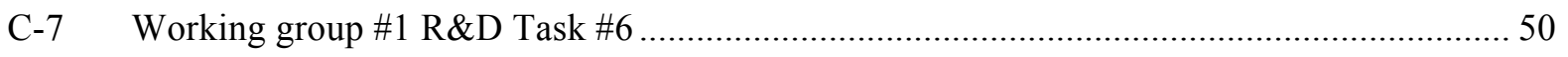

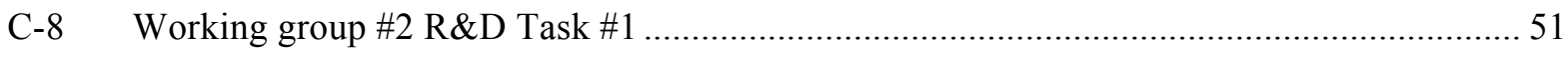

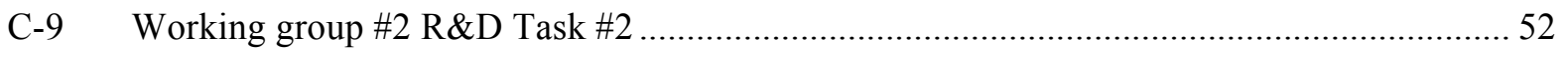

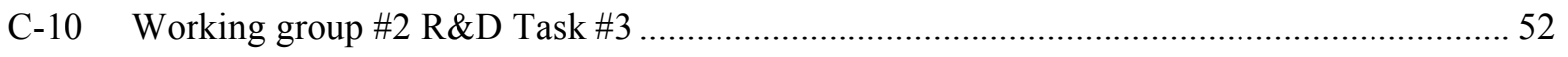

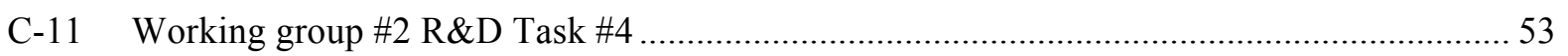

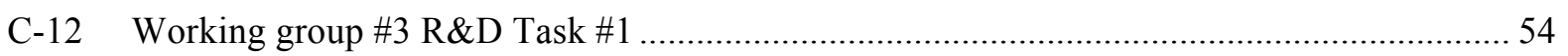

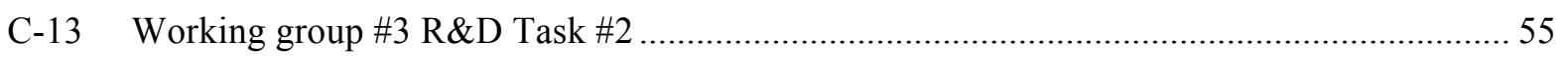

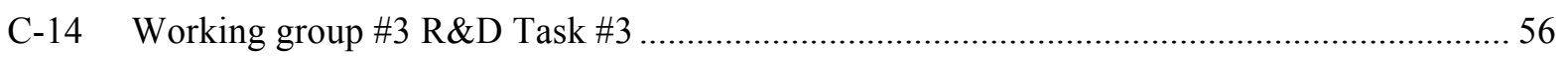

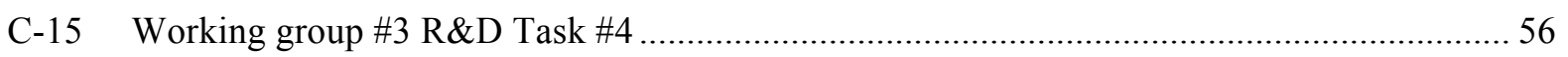

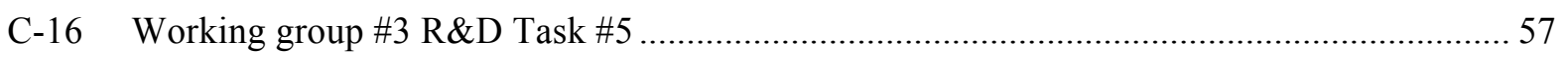

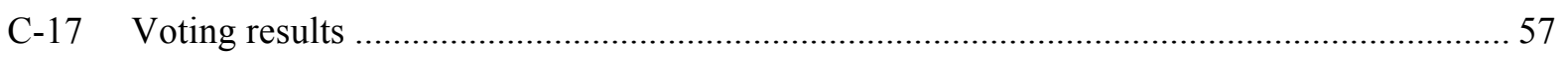





\section{ACKNOWLEDGMENTS}

This research was sponsored by the U.S. Department of Energy, Office of Nuclear Energy, for the Light Water Reactor Sustainability Research and Development effort.

The authors would like to express our appreciation to the workshop presenters who shared their technical expertise and experience with the workshop participants to set the stage for the brainstorming session. The authors would also like to express our thanks to the attendees (Appendix A) for their participation in the workshop and for continuing discussions following the workshop. Finally, the authors wish to acknowledge Yann LePape, Dan Naus, Daniel Algernon, Yi-Lung (Larry) Mo, Larry Jacobs, and John Popovics for their contributions to this report. 



\section{EXECUTIVE SUMMARY}

Materials issues are a key concern for the existing nuclear reactor fleet as material degradation can lead to increased maintenance, increased downtown, and increased risk. Extending reactor life to 60 years and beyond will likely increase susceptibility and severity of known forms of degradation. Additionally, new mechanisms of materials degradation are also possible. The purpose of the US Department of Energy Office of Nuclear Energy's Light Water Reactor Sustainability (LWRS) Program is to develop technologies and other solutions that can improve the reliability, sustain the safety, and extend the operating lifetimes of nuclear power plants beyond 60 years.

The intent of this LWRS Concrete nondestructive evaluation (NDE) roadmap is to define Research \& Development (R\&D) actions to address gaps between available NDE concrete techniques and the technology needed to make quantitative measurements to determine the durability and performance of concrete structures on our current NPP fleet. To assist in the development of this roadmap, a workshop (See Appendix B for Workshop Agenda) was held on July 31, 2012, at the Oak Ridge National Laboratory (ORNL) Conference Center with 28 attendees: three representatives from the Electrical Power Research Institute (EPRI), one representative from Electricité de France, two representatives from the US Nuclear Regulatory Commission (NRC), six representatives from universities (University of Tennessee-Knoxville, Georgia Tech, Iowa State University, University of Illinois, and University of Houston), one representative from industry (WesDyne), one representative from a non-USA nonprofit organization (Swiss Association for Technical Inspection), and 14 representatives from DOE national laboratories (ORNL, Pacific Northwest National Laboratory, Idaho National Laboratory, and Argonne National Laboratory).

A multitude of concrete-based structures are typically part of a light water reactor (LWR) plant to provide foundation, support, shielding, and containment functions. Concrete has been used in the construction of nuclear power plants (NPPs) because of three primary properties-its inexpensiveness, its structural strength, and its ability to shield radiation. Examples of concrete structures important to the safety of LWR plants include the containment building, spent fuel pool, and cooling towers. This use has made its long-term performance crucial for the safe operation of commercial NPPs.

With respect to the concrete structures, age-related degradation may affect engineering properties, structural resistance/capacity, failure mode, and location of failure initiation that in turn may affect the ability of a structure to withstand challenges in service. In order to ensure the safe operation of NPPs, it is essential that the effects of potential degradation of the plant structures, as well as systems and components, be assessed and managed during both the current operating license period as well as subsequent license renewal periods. In contrast to many mechanical and electrical components, replacement of many concrete structures is impractical. Therefore it is necessary that safety issues related to plant aging and continued service of the concrete structures are resolved through sound scientific and engineering understanding.

Unlike most metallic materials, reinforced concrete is a nonhomogeneous material, a composite with low-density matrix, a mixture of cement, sand, aggregate and water, and a high-density reinforcement (typically 5\% in NPP containment structures), made up of steel rebar or tendons. Plants have been typically built with local cement and aggregate fulfilling the design specification regarding strength, workability, and durability, but as a consequence, each plant's concrete composition is unique and complex. In addition, NPP concrete structures are often inaccessible and contain large volumes of massively thick concrete. These structures are exposed to different environments (moisture, temperature) and a diversity of degradation mechanisms (high temperatures, radiation exposure, 
chemical reactions) at different plant sites, all of which adds to the complexity of determining the integrity/quality of the concrete.

After an introduction to the challenges of making NDE measurements on thick sections of concrete as seen in NPPs, the focus of the workshop was on defining R\&D actions to address gaps between available techniques and the technology needed to make these measurements on our current NPP fleet. Several important themes were formulated.

1) Need to survey available samples

Comparative testing on the various NDE concrete measurement techniques will require concrete samples with known material properties, voids, internal microstructure flaws and reinforcement locations. These samples can be artificially created under laboratory conditions where the various properties can be controlled. In addition, concrete samples that have been removed from the field and exposed to known degradation mechanisms (different levels of radiation/temperature/chemical reaction) provide the most realistic concrete aging specimens.

2) Technique(s) to perform volumetric imaging on thick reinforced concrete sections A technique or a combination of techniques that could reliably and quickly generate an image of the volume of thick concrete structures will significantly enhance the interpretability of the outcome of the various NDE measurement methodologies and is greatly desired.

3) Determine physical and chemical properties as a function of depth Knowledge of the physical and chemical properties of a concrete structure, especially as a function of depth, will provide highly relevant information on its structural integrity.

4) Techniques to examine interfaces between concrete and other materials In some cases, the structural concrete to be inspected is covered by a steel liner. Presently there are no techniques designed for inspecting concrete through steel.

5) Development of acceptance criteria - model and validation

Through modeling and validation, an acceptance criterion needs to be developed to determine that a concrete structure is "good enough." For each NDE concrete measurement metric (void size, crack size, reinforcement degradation, physical properties), an upper and lower acceptance boundary needs to be determined.

6) Need for automated scanning system for any of the NDE concrete measurement systems Due to the massively large concrete areas to be surveyed, an automated scanning system for any NDE concrete measurements is greatly desired.

This report is organized into eleven chapters. Chapter 1 explains the importance of safely extending the lifespan of existing NPPs and provides an introduction to concrete structures. Chapter 2 describes concrete structures of interest. Chapter 3 details the general characteristics of concrete in NPPs. As part of the license renewal process, Chapter 4 describes the NRC's aging management review that includes an assessment of the applicant's proposed programs to manage aging of structures and components. Chapter 5 describes the various degradations of concrete. Chapter 6 describes in-service inspection testing as required by the NRC. Chapter 7 describes requirements for augmented NDE as these tests are not typically employed during the in-service inspection testing. Chapter 8 surveys the currently used NDE techniques used to measure concrete degradation. Chapter 9 summarizes the results from the LWRS Concrete NDE workshop held on July 31, 2012. Chapter 10 summarizes the main points of this report. Chapter 11 lists the references. 


\section{INTRODUCTION}

The US fleet of commercial nuclear power reactors has an average age of more than 30 years, and most of the fleet has either applied for or received an extension of the operating license from 40 years to 60 years [1]. The Light Water Reactor Sustainability (LWRS) Program is the primary programmatic activity that addresses Objective 1, described in the US Department of Energy Office of Nuclear Energy's 2010 Research and Development Roadmap. One of their main objectives is to develop technologies and other solutions that can improve the reliability, sustain the safety, and extend the operating lifetimes of nuclear power plants (NPPs) beyond 60 years.

As part of this effort, a LWRS Concrete NDE Workshop was held at Oak Ridge National Laboratory on Tuesday July 31, 2012. The purpose of this workshop was to develop content for the Light Water Reactor Sustainability (LWRS) Nondestructive Evaluation (NDE) for Concrete Research and Development (R\&D) Roadmap. The workshop was held at the Oak Ridge National Laboratory (ORNL) Conference Center with 28 attendees: three representatives from the Electrical Power Research Institute (EPRI), one representative from Electricité de France, two representatives from the US Nuclear Regulatory Commission (NRC), six representatives from universities (University of Tennessee-Knoxville, Georgia Tech, Iowa State University, University of Illinois, and University of Houston), one representative from industry (WesDyne), one representative from a non-USA nonprofit organization (Swiss Association for Technical Inspection), and 14 representatives from DOE national laboratories (ORNL, Pacific Northwest National Laboratory, Idaho National Laboratory, and Argonne National Laboratory).

If current NPPs do not operate beyond 60 years (due to owner decisions or regulatory restrictions), the total fraction of domestic electrical energy generated from nuclear power will begin to decline-even with the expected addition of new nuclear generating capacity, as shown in Figure 1.

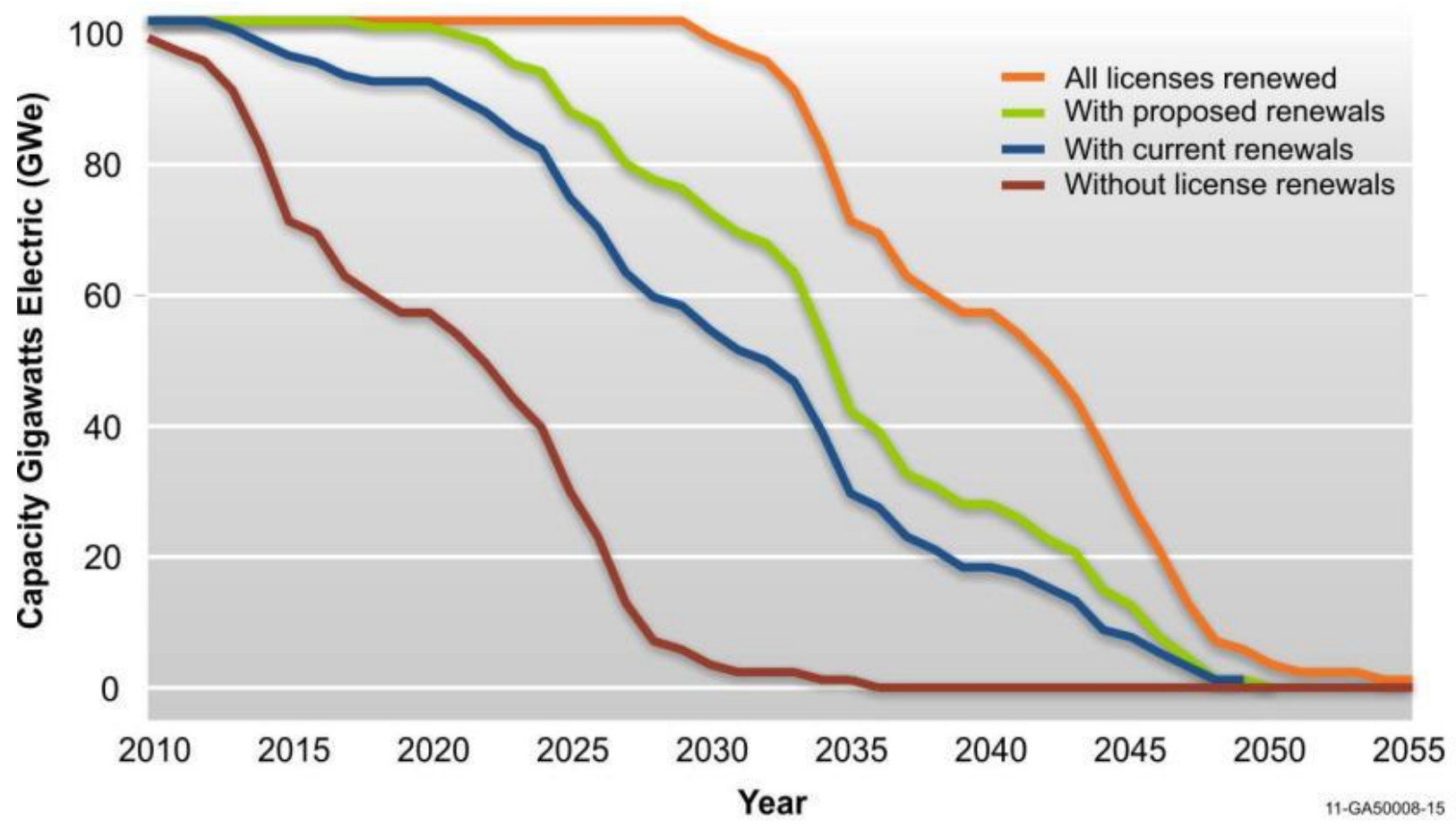

Source: http://www.nrc.gov/reading-rm/doc-collections/nuregs/staff/sr1350/v23/sr1350v23-sec-2.pdf

Figure 1. Projected nuclear power generation [2]. 
Replacing these units will require long-lead planning periods (10 to 15 years prior to unit retirement). In addition, significant capital investments (hundreds of billions of dollars) will be needed to design, construct, and commission the replacement generation capacity. Further, if the new capacity has to meet any carbon-neutral criteria (i.e., the replacement units must not produce more greenhouse gas emissions than the units being retired), the costs for replacement generation capacity will be even higher.

A multitude of concrete-based structures are typically part of a light water reactor (LWR) plant to provide foundation, support, shielding, and containment functions. Concrete has been used in the construction of NPPs because of three primary properties - its inexpensiveness, its structural strength, and its ability to shield radiation. Examples of concrete structures, important to the safety of LWR plants, include the containment building, spent fuel pool, and cooling towers. This use has made its long-term performance crucial for the safe operation of commercial NPPs. Unfortunately there is very little data on concrete performance through the life of a NPP, and these concrete structures may be some of the very few components in a NPP that cannot be replaced.

With respect to the concrete structures, age-related degradation may affect engineering properties, structural resistance/capacity, failure mode, and location of failure initiation that in turn may affect the ability of a structure to withstand challenges in service. In order to ensure the safe operation of NPPs, it is essential that the effects of potential degradation of the plant structures, as well as systems and components, be assessed and managed during both the current operating license period as well as subsequent license renewal periods. In contrast to many mechanical and electrical components, replacement of many concrete structures is impractical. Therefore, it is necessary that safety issues related to plant aging and continued service of the concrete structures are resolved through sound scientific and engineering understanding.

Unlike most metallic materials, reinforced concrete is a nonhomogeneous material, a composite with lowdensity matrix, a mixture of cement, sand, aggregate and water [3], and a high-density reinforcement (typically 5\% in NPP containment structures), made up of steel rebar or tendons. Plants have been typically built with local cement and aggregate fulfilling the design specification regarding strength, workability, and durability, but as a consequence, each plant's concrete composition is unique and complex. In addition, NPP concrete structures are often inaccessible and contain large volumes of massively thick concrete. These structures are exposed to different environments (moisture, temperature) and a diversity of degradation mechanisms (high temperatures, radiation exposure, chemical reactions) at different plant sites, all of which adds to the complexity of determining the integrity/quality of the concrete.

The intent of this LWRS Concrete NDE roadmap is to define Research \& Development (R\&D) actions to address gaps between available NDE concrete techniques and the technology needed to make quantitative measurements to determine the durability and performance of concrete structures in our current NPP fleet. The overall objective is to provide assurances that the NPP concrete structures will continue to meet their functional and performance requirements and maintain adequate structural margins during the current licensing period, as well as for continued service periods beyond the initial operating license period that may extend plant operation to 60,80 , or more years. 


\section{STRUCTURES OF INTEREST IN NUCLEAR POWER PLANTS}

\subsection{SAFETY-RELATED STRUCTURES}

A myriad of concrete-based structures are contained as a part of a LWR plant to provide foundation, support, shielding, and containment functions. Examples of concrete structures important to the safety of LWR plants include the containment building, spent fuel pool, and cooling towers.

\subsubsection{Containment Building}

The containment building serves as the final barrier to the release of fission products to the outside environment under postulated accident conditions. During normal operating conditions the containment is subject to various operational and environmental stressors (e.g., ambient pressure fluctuations, temperature variations, earthquakes, ingress of hostile ions such as chlorides, and wind storms). Ensuring that the structural capacity and leak-tight integrity of the containment has not deteriorated unacceptably from either aging or environmental stressor effects is essential to reliable continued service evaluations and informed aging management decisions.

The containment structure generally consists of a concrete basemat foundation, vertical cylindrical walls, and dome. The containment can be fabricated from reinforced concrete or a combination of reinforced and post-tensioned concrete. Leak tightness of containment is provided by a steel liner attached to the containment inside surfaces. Depending on the functional design (e.g., large dry or ice condenser), the concrete containments can be on the order of 40 to $50 \mathrm{~m}$ in diameter and 60 to $70 \mathrm{~m}$ high, with wall and dome thicknesses from 0.9 to $1.4 \mathrm{~m}$, and base slab thicknesses from 2.7 to $4.1 \mathrm{~m}$.

\subsubsection{Spent Fuel Pool}

The spent- and new-fuel storage pools for pressurized water reactor (PWR) plants are typically located in an auxiliary building proximate to the containment. These reinforced concrete wall and slab structures are generally massive in cross section to support a large pool of water and the fuel elements. They are lined on the water side with stainless steel. The pools are connected to the reactor/refueling cavity (inside containment) via a transfer channel that is also a safety-related structure since it must provide radiation shielding and support for the fuel transport mechanism and fuel.

\subsection{COOLING TOWERS}

Cooling towers are used in closed-cycle water systems to remove waste heat from the main condenser loop. Cooling towers, used as the primary heat sink, are considered Class I structures and are designed to withstand natural phenomena (e.g., earthquakes and tornadoes). Concrete cooling towers are divided into two categories: atmospheric or natural draft cooling towers (NDCTs) and mechanical draft cooling towers (MDCTs). The NDCT hyperbolic shell is generally a reinforced concrete structure having a typical height between 120 and $175 \mathrm{~m}$ (in France, can go up to $200 \mathrm{~m}$ ), shell thickness from 25 (neck) to $40 \mathrm{~cm}$, and crown/cornice diameter about $80 \mathrm{~m}$. Mechanical draft cooling towers are usually prefabricated and can be either assembled on site or at the factory. Different materials are used for these towers, with concrete being the preferred material for the water basins in all of them. During operation, concrete inside the NDCT shell is subjected to a temperature around $40^{\circ} \mathrm{C}\left(104^{\circ} \mathrm{F}\right)$ and relative humidity of $100 \%$. The "natural" chemistry of the intake water varies from one plant to the other. It is notable that some plants use municipal retreated water containing chlorides or brackish water. 


\section{GENERAL CHARACTERISTICS OF CONCRETE IN NUCLEAR POWER PLANTS}

\subsection{MULTI-SCALE/MULTI-PHYSICS PROBLEM}

\subsubsection{Structural Scale and Difficulties Associated with Large-Scale Structures}

Concrete structures in nuclear generating stations are extremely large. For example, the height of an atmospheric cooling tower is about $120-150 \mathrm{~m}$, and a containment building is nearly $60 \mathrm{~m}$ high. Though this situation is not unique (hydro-dams, long-span bridges), it poses major difficulties in terms of inspection due to the following.

- The relative heterogeneity of the concrete pours (spatial variation of the materials properties)

- Variability in the placement of the reinforcement/tendon ducts due to the construction process

- Differences in environmental exposure (sun, rain, dominant wind, etc.), which affect the concentration of aggressive species on the surface and the moisture content in the concrete cover

- A significant portion of the structure that is inaccessible (below-grade structures, high radiation zone, etc.)

Hence, completion of a full NDE mapping of the structure is currently out of reach, which, first, raises the question of the structural significance and the interpretation of "discrete" monitoring and, second, drives the need for developing faster automated techniques.

Safety-related structures (containment building and spent fuel pool) are massive (thickness of over $1.5 \mathrm{~m}$ ) and heavily reinforced. Consequently, the following must be considered.

- The heat release resulting from the cement hydration deep in the bulk of the structure (quasiadiabatic condition) may create thermal cracking on a generally cooler surface unless proper insulating conditions are provided. This phenomenon is sometimes referred to as thermal shrinkage. Further differential autogenous/drying shrinkage between successive pours may also cause cracking through the wall. The temperature elevation in the bulk (if higher than about $70^{\circ} \mathrm{C}$ ) may also be responsible for a delayed swelling mechanism that is potentially detrimental to the structural integrity.

- The structure will retain a high level of moisture content (though gradually evolving) that favors creep and, if other conditions are met, the formation of an alkali aggregate reaction.

- The large volume to be poured, the presence of a high density of steel elements (reinforcement, post-tensioning system, penetrations), and the lack of correct vibration may cause local formation of air pockets or honeycombs.

\subsubsection{Mesoscale and Difficulties Associated with Compact Composite Material}

At the mesoscale ( $1 \mathrm{~mm}$ to $20 \mathrm{~cm}$ ), compact composite material appears as a three-phase composite.

- The matrix is composed of a hardened cement paste (described in the next section).

- About $70 \%$ of the volume fraction is occupied by aggregates of different sizes (and sometimes mineralogy) that are densely organized. Their relative compaction and intrinsic quality are essential to the mechanical properties of concrete. A large variety of aggregates are suitable for building concrete (limestone, sandstone, granite, basalt, siliceous aggregate, etc.). Some particular aggregate (amorphous forms of silica and some carbonates) may result 
in reactive expansion of concrete. The size of the largest aggregate is about $2-3 \mathrm{~cm}$ for most of concrete used in the construction of NPPs.

- Entrapped air bubbles in a small volume fraction ( $1-3 \%)$ provide some expansion volume if subjected to freeze.

\subsubsection{Microscale and Difficulties Associated with a Heterogeneous Multi-phase Material}

At the microscale $(1-100 \mu \mathrm{m})$, the hardened cement paste contains the following.

- A solid skeleton is essentially made of poorly crystallized hydrates (C-S-H) of undetermined shape and other more or less crystallized forms (e.g., Portlandite, sulfo-alumninate).

- Capillary pores (about $20-30 \%$ in volume fraction at this scale) of distributed sizes are partially connected to form a tortuous network. The pores are partially filled with gas and interstitial water containing various ions (mainly alkali). Other ionic species may also be found as the result of external aggression. Gas-water equilibrium causes capillary pressure that affects the moisture transport and the effective diffusion of ionic species.

The transition between the hardened cement paste and aggregate may be gradual or sharp, depending on the type of aggregate used. When gradual, the interfacial transition zone (size about $10-100 \mu \mathrm{m}$ ) is generally more porous than the bulk paste and contributes greatly to the transport and electrical properties of concrete.

\subsection{USE OF LOCAL MATERIALS}

Concrete is the most used material in the world because it is comparatively inexpensive, provided shipping costs remains affordable. Hence, NPPs have been built with local cement and aggregate fulfilling the design specifications regarding strength, workability, and durability. As a consequence, the composition of concrete in a particular plant is likely to be unique and different from other plants, even though similar specifications may have been initially prescribed for those plants.

The construction of an NPP is a long process that takes place over several years, during which time the cement composition and the aggregate quality may change.

\subsection{INTERACTION WITH STEEL}

Safety-related structures have a high reinforcement ratio of about $5 \%$ (compared to $2 \%$ in common buildings) to ensure their safety function under accidental loadings (containment pressurization, impact, earthquake). The reinforcement consists of one or more layers of rebar (typically of size \#6 or \#8) meshes in the inner and outer portions of the wall. The presence of the rebar creates a shadow effect that complicates any inspection, based on nondestructive techniques, of the concrete located behind it. The cover thickness is usually greater for safety-related structures (about $2-3$ in.). By comparison, the cover specification for cooling tower is only about $1 \mathrm{in}$. The difficulties associated with placement result in significant discrepancies regarding the actual locations and covers when compared with the design drawings. Hence, locating the rebar (and other embedded steel components) in the portion of the structure to be inspected is mandatory.

Some containments are post-tensioned in one or two directions. In general, the tendon ducts are ungrouted and filled with grease for corrosion protection. The ducts are located deeper in the containment. 
Containment buildings and spent fuel pools are lined with carbon and stainless steel, respectively. The containment steel is a radiological barrier in case of an accidental release of nuclides from the reactor or the primary cooling system. The spent fuel pool (and the transfer canal) ensures the leaktightness of the pool filled with borated water to poison the radiological activity of the used fuel. The liner is also used as a formwork during construction. The liner-concrete connection can be ensured by Nelson studs and other steel connectors. Behind the liner, the unilateral contact between the liner and concrete may not be ensured as the result of concrete shrinkage, and in some observed cases, bulging of the liner has occurred.

\subsection{DIFFERENT ENVIRONMENTS}

Concrete is in constant interaction with the environment due to its natural porosity. Many outdoor concrete structures of interest are subjected to significantly different climates, which results in a variety of potential degradations.

- A hot-humid marine climate is extremely detrimental to reinforced/pre-stressed concrete structures in that it causes corrosion.

- A cold climate may trigger freeze-thaw degradation. In addition, increasing use of deicing salt in the northern states may cause corrosion.

- Sulfate and phosphate contained in the ground are other sources of degradation in belowgrade structures.

\subsection{EVOLUTION OVER TIME}

Concrete undergoes changes in its material properties from the minute the constituents are mixed together until decommissioning of the plant. Hydration (i.e., chemical reactions that transform cement into hydrated phases) causes a porous microstructure to develop that becomes denser over time. This decrease in porosity results in the hardening of concrete (increase of mechanical and durability properties). Though it is generally thought that most of the hydration is completed after 28 days, providing the time baseline for structural design, it is not unusual to observe a significant increase in the compressive strength after several years, suggesting a continuous hydration or a densification of the material. This increase in the strength of concrete is generally described by the term "hardening."

The solid skeleton remains in chemical interaction with the ions in the interstitial water partially filling the capillary pores. These interactions can dissolve existing hydrates and eventually precipitate new forms, resulting in a microstructural evolution. Another type of degradation is associated with mechanical or coupled chemical-mechanical reactions that create micro-cracks in the cement paste, sometimes in and/or around the aggregate or the embedded steel. All these adverse mechanisms are generally referred to as aging of concrete. 


\section{OPERATING EXPERIENCE}

As part of the license renewal process, the NRC conducts an aging management review that includes an assessment of the applicant's proposed programs to manage aging of the structures and components. One of the elements associated with an assessment of an aging management program addresses operating experience, and for the concrete structures this includes a walk-down of areas of interest (e.g., buildings, spent fuel pool, supports, masonry walls, and water-control structures).

Although continuing the service of a NPP past its initial operating license period is not expected to be limited by environmentally related degradation of the concrete structures, occurrences of age-related degradation have been observed. Examples of age-related degradation include corrosion of steel reinforcement in water intake structures, corrosion of post-tensioning tendon wires, rock anchor/tendon coupling failure, leaching of tendon gallery concrete, greater-than-anticipated loss of prestressing force, concrete spalling at containment buttress, water infiltration, and leakage of corrosion inhibitors from tendon sheaths. Other examples include cracking and spalling of the containment dome concrete due to freeze-thaw damage, low strengths of tendon wires, and corrosion of concrete containment liners (interior areas as well as backside areas adjacent to concrete).

Recently, concrete cracking due to alkali-silica reactions was identified at one plant, and internal concrete cracks associated with architectural features of a shield building were observed at another plant during construction of an opening to replace the reactor pressure vessel head. Also, leakage of water from spent fuel pools and refueling cavities has occurred at several plants that may potentially result in erosion of the concrete or corrosion of the carbon steel components it contacts, particularly for PWRs that utilize borated water. A review of plant operating experience indicates that aging degradation of concrete has primarily been in the form of cracking/spalling/loss of material due to aggressive chemical attack. 


\section{DEGRADATION OF CONCRETE}

Service-related degradation can affect the ability of NPP containment to perform satisfactorily in the unlikely event of a severe accident by reducing its structural capacity or jeopardizing its leak-tight integrity. Containment degradation is considered to be any phenomenon that decreases its loadcarrying capacity, limits its ability to contain a fluid medium, or reduces its service life. The root cause for containment degradation can generally be linked to a design or construction problem, inappropriate material application, a base-metal or weld-metal flaw, maintenance or inspection activities, or excessively severe service conditions.

\subsection{CONVENTIONAL CLASSIFICATION (KNOWING THAT THE DEGRADATION MODES MAY BE COUPLED)}

i. Chemical

- Acid attack (sulfuric, boric) and other forms of leaching

- Reactive transport: external sulfate/phosphate attack

- Internal swelling reaction [delayed ettringite formation (form of internal sulfate attack) and alkali-aggregate reaction] causing the formation of secondary products (silicocalcite gel or delayed ettringite) and creating some pressure in various locations/phases of the material (see also mechanical degradation)

ii. Physical

- Freeze-thaw

- Thermal damage causing microstructure changes possibly affecting the vicinity of steam penetrations

iii. Irradiation with an increase in temperature

iv. Mechanical

- Shrinkage: self-induced mechanical contraction produced by self-desiccation or drying (moisture transport)

- Creep (active for post-tensioned containments): delayed deformation caused by a sustained loading coupled with the presence of water in the capillary pores and moisture transport

- Fracture: concrete is a quasi-brittle material with poor tensile strength. Low tensile stresses (a few MPa) will result in cracking at the mesoscale

- Internal swelling reaction: the pressure resulting from the formation of expansive gel or secondary hydrates generates some swelling in the mechanically unconfined direction (i.e., more expansion deformation is observed in the less-reinforced direction). In restrained directions, the gel pressure generates compressive stresses.

\subsection{SCALE AND KINETICS}

\subsubsection{Chemical/Physical Attacks}

The degradation is initiated from the surface and gradually penetrates the material. In first approximation, the kinetics of penetration is generally controlled by diffusion (Fick's laws, penetration depth being a square root function of time).

The apparent diffusion coefficient depends on the aggressive substance and the morphology of the 
porous network in concrete (pore size distribution, tortuosity, connectivity). After several decades, the penetration depth can reach a few inches, affecting the concrete cover, potentially the rebar, and eventually a limited area beyond the rebar. When tendons are present, diffusion-controlled penetration through the bulk of concrete is not sufficient to reach the ducts deeply embedded in the containment wall. However, the ingress of aggressive species may occur around the tendon anchorage (poor maintenance of the tendon cap, local cracking of concrete).

The transport of aggressive species is whether highly reactive (boric/sulfuric acid, sulfate) weakly reactive (carbonation), or even nonreactive (chloride for instance, though partial binding with the hardened cement paste is observed). When chemical reaction with the different phases of the cement paste or the aggregate is observed, it usually leads to a dissolution/precipitation process that affects the microstructure of the material, and hence, the physical and mechanical properties (e.g., elasticity, strength).

When the aggressive species reach the embedded steel components (usually the reinforcement layer), favorable conditions for steel corrosion may develop (typically resulting from carbonation and chloride attack, reducing the original basic $\mathrm{pH}$ of concrete to a level triggering de-passivation of the rebar). Corrosion of the steel elements causes a reduction of the steel section and a decrease in the mechanical properties (ductility and strength particularly). At a later stage, the formation of expansive corrosion products around the steel elements may cause cracking, spalling, and delamination of the concrete cover. The degradation of steel elements and concrete cover has a significant impact on the bearing capacity of the structure, especially where the thickness is limited (e.g., cooling tower, buried pipe).

Primary degradation mechanisms that potentially can cause physical damage to the containment liner include (1) general corrosion (atmospheric, aqueous, galvanic, stray electrical current, and general biological); (2) localized corrosion (filiform, crevice, pitting, and localized biological); (3) mechanically assisted degradation (erosion, fretting, cavitation, corrosion fatigue, surface flaws, arc strikes, and overload conditions); (4) environmentally induced cracking (stress corrosion and hydrogen induced); and (5) fatigue. Material degradation due to either general or pitting corrosion represents the greatest potential threat to the containment liner. The main difficulty for an inspection is when the corrosion pitting has been initiated from the side in contact with concrete.

\subsubsection{Irradiation with an Increase in Temperature [4]}

Radiation can affect concrete in two mechanisms. One is the change in the material properties caused by the radiation interactions with the material. Such damage might be the breaking of the bonds in the material or embrittlement of the material. The second possible cause might be the localized heating of the concrete caused by the absorption of the radiation energy. In many cases, it has not been possible to distinguish between the two mechanisms when concrete degradation has been identified.

The effects of low doses, $<10^{10}$ neutron $/ \mathrm{cm}^{2}$ or $10^{10}$ Gy gamma, of radiation over periods of less than 50 years do not seem to have a significant effect on the concrete. This is supported by existing research and standards published by ASME and ANSI. Longer-term exposure, over 100 years, has not been studied.

The effects of higher doses of radiation are not as clear, and some differences in reported results exist. For some concretes, neutron exposures $>10^{10}$ neutron $/ \mathrm{cm}^{2}$ may cause a reduction in compressive and tensile strength and may depend on the neutron energy spectrum and the composition of the concrete. 
For high radiation exposure, $10^{20}$ neutron $/ \mathrm{cm}^{2}$ or $10^{10}$ rads of gamma, concrete has been reported to exhibit a reduction in compressive and tensile strength and a marked increase in volume, due to the expansion of the aggregate and the shrinkage of cement paste. It was not possible to determine if these effects were caused by the heating and loss of water or by direct radiation effects. Regardless, deleterious effects were reported.

The effects of long-term exposure of concrete to elevated temperatures are a loss of water in the concrete, leading to a decrease in compressive strength, changes in the modulus of elasticity, creep resistance, conductivity, and diffusivity. Generally speaking, the threshold of degradation is $95^{\circ} \mathrm{C}$, and the effects increase with increasing temperature and time exposure. Rapid temperature increase or thermal cycling can lead to significant concrete degradation.

\subsubsection{Mechanical Loading}

Permanent loadings susceptible to developing significant long-term time-dependent deformation are limited to the sustained compression of concrete induced by the post-tensioning system, resulting in a permanent stresses-to-compressive strength ratio of about $1 / 3$. Locally, around penetrations (equipment and personnel hatches, steam penetration), the distortion of the tendon profile may create shear and/or lower compression state. These areas are more prone to cracking (potentially fracturecreep interaction) in conjunction with accidental loading and prestressing losses.

Potentially the most detrimental form of time-dependent mechanical loading is the formation of expansive gel/secondary hydrates caused by alkali-aggregate reaction (AAR) or delayed ettringite formation, respectively. The kinetics of these mechanisms is usually slow, and visible signs of degradation generally appear after several decades (often 30-40 years) for massive structures (operating experience including dams). The degradation may affect the whole or large portions of the structure. Areas more humid (below-grade structures for instance) are more prone to AAR. 


\section{IN-SERVICE INSPECTION TESTING}

In-service inspection programs for NPP structures have the primary goal of ensuring that the structures have sufficient structural margins to continue to perform in a reliable and safe manner. A secondary goal is to identify environmental stressors or aging factor effects before they reach sufficient intensity to potentially degrade structural components.

One of the conditions of all operating licenses for water-cooled power reactors in the United States is that the primary reactor containment shall meet the containment leakage test requirements set forth in Appendix J, "Primary Reactor Containment Leakage Testing for Water-Cooled Power Reactors," to Title 10, "Energy," Part 50 of the Code of Federal Regulations (10 CFR 50). Contained in this regulation are requirements pertaining to Type $\mathrm{A}, \mathrm{B}$, and $\mathrm{C}$ leakage-rate tests that must be performed by each licensee as a condition of their operating license. Type A tests are intended to measure the primary reactor containment overall integrated leakage rate (1) after the containment has been completed and is ready for operation and (2) at periodic intervals thereafter. Type B tests are intended to detect local leaks and to measure leakage across each pressure-containing or leakage-limiting boundary for primary reactor containment penetrations (e.g., penetrations that incorporate resilient seals, gaskets, or sealant compounds; and air-lock door seals). Type $\mathrm{C}$ tests are intended to measure containment isolation valve leakage rates. Appendix $\mathrm{J}$ also requires a general visual inspection of the accessible interior and exterior surfaces of the containment structures and components to uncover any evidence of structural deterioration that may affect either the containment structural integrity or leaktightness. Section XI, Subsection IWL of the ASME Code addresses reinforced and post-tensioned concrete containments (Class CC). Two examination categories are provided in Subsection IWL. Examination Category L-A addresses accessible concrete surfaces and examines them for evidence of damage or degradation, such as cracks. The concrete is examined at 1,3 , and 5 years following the containment structural integrity test and every 5 years thereafter. The primary inspection method of Category L-A is visual examination (general or detailed). Examination Category L-B addresses the unbonded post-tensioning system. The unbonded post-tensioning system examination schedule is the same as for the concrete. For post-tensioned concrete containments, tendon wires are tested for yield strength, ultimate tensile strength, and elongation. Tendon corrosion protection medium is analyzed for alkalinity, water content, and soluble ion concentrations. Prestressing forces are measured for selected sample tendons. Subsection IWL specifies acceptance criteria, corrective actions, and expansion of the inspection scope when degradation exceeding the acceptance criteria is found. Additional requirements for inaccessible areas are specified in 10 CFR 50.55a(b)(2)(viii). The acceptability of concrete in inaccessible areas is to be evaluated when conditions exist in accessible areas that could indicate the presence or result in degradation to such inaccessible areas. Guidelines for the evaluation of existing nuclear safety-related concrete structures (other than containments), including acceptance criteria, have been developed by organizations such as the American Concrete Institute. Information on aging management programs for NPP masonry walls and water-control structures also is available. Inspection requirements for steel containments and liners of concrete containments are contained in Section XI, Subsection IWE of the ASME Code. Acceptable editions and addenda of the ASME Code are identified in 10 CFR 50.55a. 


\section{REQUIREMENTS FOR AUGMENTED NONDESTRUCTIVE EVALUATION}

Nondestructive examination methods are not typically employed as part of the in-service inspection and testing of containments. Nondestructive testing of containment structures has generally been conducted to determine if degradation has occurred or to quantify degradation that is known to be present.

Though some indications are provided in ACI 349.3R-02, a clear and well-accepted description of the size of the degradation (local flaw like an air pocket or larger defect such as a delamination or a chemical attack on a large portion or the structure) needs to be better defined. The criticality of a flaw depends on the type of structure, its location, its extent, and its structural significance in terms of impact on functioning of the studied structure. A joint effort from the regulator, the industry, and the research community is desirable to better assess "acceptance criteria" that could serve as a basis to evaluate the significance and reliability of existing and new nondestructive techniques.

\subsection{CHEMICAL/PHYSICAL ATTACKS}

Monitoring the ingress of the aggressive species (external chemical transport) or the extent of the damaged area (physical attack and reactive transport) by

- the change of ionic content in the interstitial water (typically the chloride content),

- the evolution of the elastic/electromagnetic properties caused by the dissolution/precipitation process (the contrast with the bulk properties might be low though).

Monitoring the engendered degradation

- $\quad$ In concrete

- Microstructure evolution (dissolution/precipitation)

- Mesostructure evolution (cracking/spalling/delamination)

- Corrosion activity in embedded steel elements

- Passive reinforcement

- The probability of corrosion activity can be evaluated by electrochemical measurement. ASTM and RILEM provide guidelines for the use and the interpretation of half-cell potential technique. Though the operating experience regarding half-cell potential is satisfactory, the necessity to be connected to the steel element is a major disadvantage for fast measurements.

- The loss of steel section is crucial information to assessment of the extent of damage and the qualitative assessment of the residual structural bearing capacity. There is currently no technique available to measure the actual steel section of corroded rebar.

- The kinetics of degradation (corrosion rate) is important for the prognosis of the residual lifespan of the structure. Electrochemical techniques (potentiostatic/galvanostatic polarization, impedance spectroscopy) can theoretically measure the corrosion rate but have insufficient reliability to be used for practical purposes.

- Liner

- The stainless steel liner of spent fuel pool is not likely to corrode. Cracking of the plug welds has been observed though.

- Corrosion of the accessible face of the containment carbon steel liner is unlikely. However, the portion of the liner embedded in the concrete basemat or in contact with concrete (inaccessible face) may under certain condition be subjected to localized corrosion (pitting) resulting from unexpected ingress 
of water or the presence of undesirable plastic or organic objects left over during the construction. Detecting the corrosion initiation at an early stage is desirable.

- Post-tensioning tendons strands may be subjected to stress-corrosion cracking if unprotected (grease leakage for instance; possibly hydrogen embrittlement). The monitoring of the tendon integrity (a failure releasing a high amount of energy) is desirable. However, tendons are inaccessible, nor are the tendon heads embedded in the anchorage plate (button head of tensioned rods may be more accessible).

Monitoring the deformation of the chim (anchorage zone) or the concrete around the tendons may be an interesting alternative.

- Pretensioned tendons (found in some precast elements; e.g., in mechanical draft cooling towers) exhibit similar issues as passive reinforcement embedded steel elements. Corrosion is an even more acute problem as corroded prestressed elements may exhibit brittle collapse.

All nondestructive techniques used to evaluate the condition of the concrete cover will face the following problems.

- The depth of degradation is likely to be limited to a few inches and thus is related to a volume of concrete that is not a representative volume of material per se. Thus, continuum medium theories may not apply.

- The moisture content is likely to vary with the depth as the result of drying or drying-wetting cycles. The resulting moisture content gradient will affect the effective materials properties on a short length scale. The separation of this effect from the true aging process might be arduous.

- Other concurrent degradation may also be a source of perturbation for the propagation of acoustic or electromagnetic waves (carbonation for instance).

\subsection{TIME-DEPENDENT MECHANICAL ACTIONS}

When subjected to an internal swelling mechanism, the structural integrity is under particular scrutiny: how will the modification of the internal stress-strain states and the material damage affecting the bulk of the structure impact the ultimate structural bearing capacity if subjected to an accidental loading (particularly regarding a seismic event)?

The lack of prior monitoring (not required by the current inspection rules) does not permit the internal strain/stress/damage states to be evaluated. Testing concrete cores taken from the bulk of the structure is not only a fastidious task but may also provide only partial, though useful, information about the internal damage if subsequent testing is performed correctly. The damage is likely to be anisotropic as a result of the anisotropy of the reinforcement.

Therefore, there is also a need to develop nondestructive techniques to evaluate the internal stresses and damage in the bulk of the structure.

\subsection{IMAGING AND DETECTION OF DEFECT IN MASSIVE STRUCTURE}

Localization of embedded steel component and construction voids or honeycombs in concrete is not monitoring of age-related problems as results of the construction per se but is a crucial part of the desirable augmented inspection program. 


\section{CURRENTLY USED NDE TECHNIQUES FOR MEASURING CONCRETE DEGRADATION}

\subsection{VISUAL INSPECTION}

Visual inspection is an important first step that can provide valuable preliminary information on the condition of the concrete [5] [3]. Experienced personnel should be able to identify signs of distress such as cracks, pop-outs, spalling, disintegration, color change, weathering, staining, surface blemishes, and lack of uniformity. In addition to present defects, a good visual survey should also include the current and past uses of the structure, the condition of adjacent structures, and the environmental conditions such as temperature and moisture [3].

There are a number of tools commonly used during visual inspections. Measuring tape, rulers, and markers are useful for denoting and measuring cracks, while thermometers and anemometers aid in assessing the environmental conditions. When access to the structure is difficult, binoculars, borescopes, endoscopes, cameras with zoom lenses, and other such remote sensing devices prove quite useful. Conversely, portable microscopes, magnifying glasses, and crack width gauges are invaluable when close-up examination is required [3].

\subsection{GROUND PENETRATING RADAR}

Ground-penetrating radar (GPR), also called impulse radar, has been used in the field of geology for quite some time but is also very useful for the inspection of concrete [3]. Electromagnetic waves are transmitted into the concrete by an antenna and will be reflected when they encounter an interface of materials with differing dielectric properties such as the interface between the concrete and reinforcing steel, voids, or defects. These reflections are then recorded by a second antenna, which is typically in the same housing as the first. If the propagation velocity of the electromagnetic wave is known, the propagation time to the interface and back can be related to the depth of the feature or flaw [6].

Typical instrumentation for GPR consists of an antenna, a control unit, a display device, and a storage device. The antenna can be either air coupled or ground coupled. An air-coupled antenna does not need to be in contact with the structure in order to take measurements, while a ground-coupled antenna does require direct contact [7]. Air-coupled antennas offer convenience and a high pace of work since they can be moved over the surface of the structure continuously. However, they must maintain a constant distance to the surface in order to avoid variations in antenna field patterns [6].

GPR has several advantages. Most notably, it is capable of being a rapid, non-contact method of obtaining depth and thickness measurements. Also, since electromagnetic waves are unable to penetrate metals, GPR is very sensitive to embedded metals such as reinforcing steel. Finally, GPR can be used in a limited capacity to detect corrosion. A corrosive environment is indicated by the blurring of rebar image features [3] [5] [6] [7] [8].

Despite the advantages of GPR, it is not without its limitations. Perhaps the most important limitation is that its depth of penetration is typically not sufficient for application within a NPP. GPR can typically be expected to penetrate up to about $0.6 \mathrm{~m}$, although penetration of up to $1 \mathrm{~m}$ has been reported [3]. Since concrete walls in NPPs can be as thick as $1.2 \mathrm{~m}$, this depth of penetration is not sufficient. Another limitation is that the interpretation of data can be quite subjective, requiring experienced personnel to use their best judgment [7]. An example of GPR output is shown in Figure 2. Finally, since electromagnetic waves cannot penetrate metals, the presence of a metal 
liner can become a complicating factor. Similarly, reinforcing steel creates a considerable shadow effect, making it difficult to detect features beneath the first layer of rebar [3] [6].
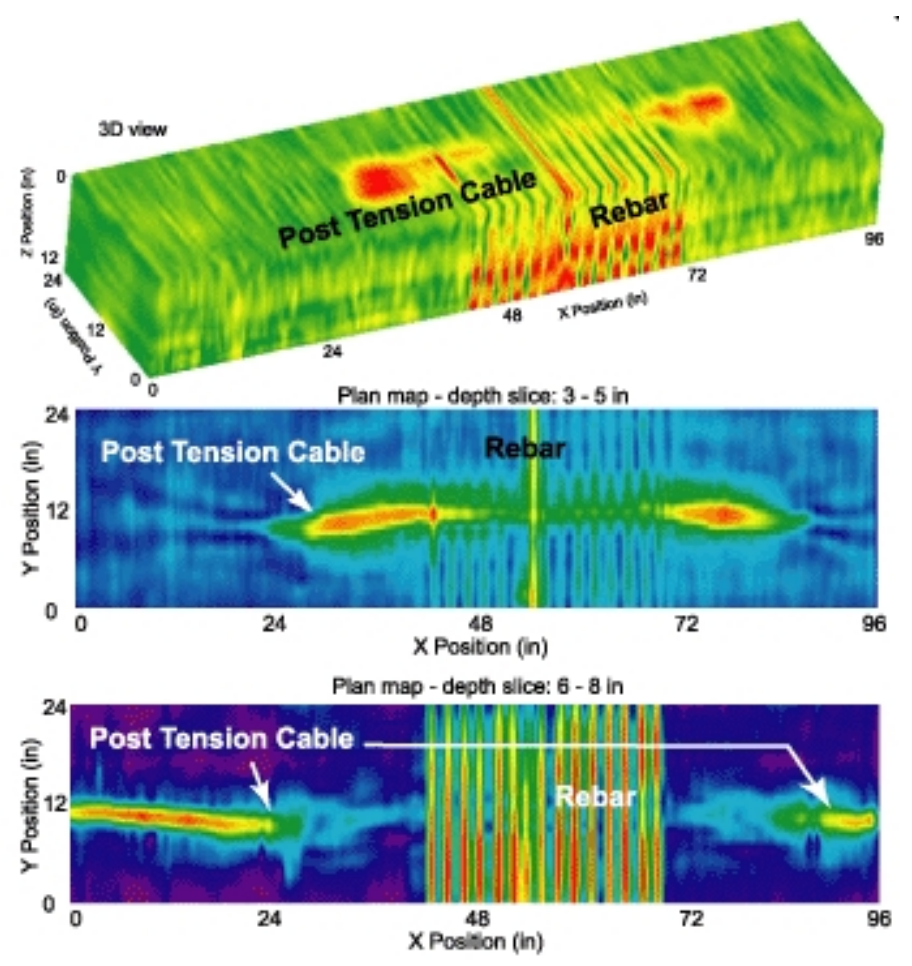

Figure 2. Example of Ground Penetrating Radar. [9]

\subsection{ULTRANSONIC TESTING}

Ultrasonic testing methods have a wide range of applications including thickness measurement, locating steel reinforcement and tendon ducts, and characterization of surface cracks. It also shows promise for investigating grouting conditions inside grouted tendon ducts. Unlike electromagnetic waves, acoustic waves are capable of penetrating metal components such as liners [6]. Ultrasonic methods can also use the Synthetic Aperture Focusing Technique (SAFT) to produce an image . Many forms of ultrasonic testing exist, but the most promising for NPP applications are pulse velocity, pulse echo, impact echo, and coda wave interferometry.

\subsubsection{Ultrasonic Pulse Velocity}

Ultrasonic pulse velocity is based on transit time of longitudinal stress waves. A transmitting transducer emits an ultrasonic pulse into the concrete which creates both shear and longitudinal stress waves. Since the longitudinal waves will reach a receiving transducer first, an electronic timing device can be used to measure the transit time. Any voids or defects encountered along the way will alter the expected transit time [3].

Although this method requires two transducers, a transmitter and receiver, it is quite flexible in their placement. Transducers can be placed on opposite faces (direct transmission), adjacent faces (semidirect transmission), or the same face (indirect transmission). However, placing them in direct 
transmission will typically give the best results. Using indirect transmission, while still acceptable, will tend to give the worst results of the three. Figure 3 shows the three placement options [3].
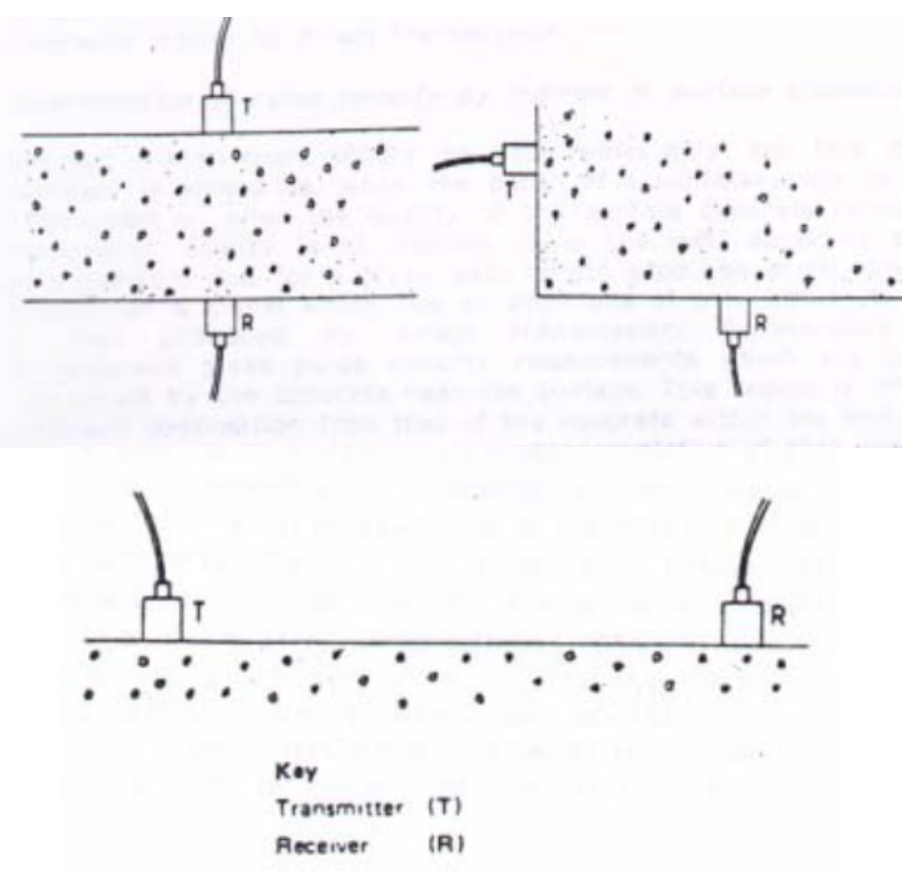

Figure 3. Placement of ultrasonic transducers [3].

\subsubsection{Ultrasonic Pulse Echo}

Ultrasonic pulse echo uses the same impulse echo principle as radar. Ultrasonic waves are reflected at interfaces where acoustic impedance differs, and the propagation time to the interface and back can be measured to learn about the interior of the structure. This method is a bit more flexible than ultrasonic pulse velocity because it only requires one transducer that both transmits and receives. This means it also only requires access to one side of the structure, which is invaluable in an environment such as a NPP. The one drawback to this method is that the speed of sound in the concrete to be tested must be known before testing can begin. This often, but not always, requires drilling cores for testing [3].

Ultrasonic pulse echo can benefit from the use of multi-sensor arrays. These arrays use multiple sensors, typically 10-12, that can both transmit and receive. Only one transducer acts as the transmitter at a time, while the rest act as receivers. Once the first has transmitted, the next sensor becomes the transmitter. This cycle continues until each transducer has acted as a transmitter. Multisensor arrays are quite promising in that they offer increased sensing area as well as increased depth of penetration, reportedly up to $2 \mathrm{~m}[10]$. 


\subsubsection{Coda Wave Interferometry}

Coda wave interferometry (CWI) is a technique that allows one to observe differences in the coda portion of a diffuse field. When an ultrasonic wave is emitted into a concrete specimen, the heterogeneous nature of the concrete causes the wave to become highly scattered and a diffuse field is created. A diffuse field consists of two parts: the first arrival and the diffuse portions, which includes the late coda contribution. Diffuse waves undergo multiple scattering, which causes them to arrive much later than the first arrival. However, diffuse waves are much more sensitive to small changes in the concrete medium and carry more information than the first arrival. CWI compares two different time series of coda waves, such as stressed state and unstressed state, and determines the degree of correlation. Comparing the difference between the two states allows one to monitor damage progression in the concrete specimen [11].

There are two types of CWI: the doublet technique and the stretching technique. The stretching technique is the more advanced of the two and is more commonly used. This technique is performed by scaling the time access so as to stretch a waveform. The time axis is stretched or compressed until it has much in common with a reference time signal. Since time and velocity are proportional, the relative velocity can be calculated from the scaling factor [11].

CWI appears to be quite useful for detecting changes and monitoring the progression of damage in concrete. However, it does not seem to be able to locate defects. It also requires a high signal-to-noise ratio to be effective in the field [11].

\subsection{IMAPCT ЕСНО}

Impact echo is similar to the ultrasonic pulse echo technique, and it is typically used to locate large voids and delaminations in plate-like structures. A mechanical impact on the surface of the concrete generates compression, shear, and surface waves. The mechanical impact is caused by spherical impactors ranging from $3 \mathrm{~mm}$ to $19 \mathrm{~mm}$. The diameter of the impactor should be varied until a clear dominant frequency is found. The compression and shear waves are reflected at internal interfaces and external boundaries, and then returned to the surface where they are received by a transducer. A digital oscilloscope is used to display the results, and an amplitude-vs.-frequency plot is created. The peaks of this plot represent dominant frequencies, and the distance to the reflecting surface can be calculated based on these peaks [3].

Impact echo has traditionally been a point testing method, but researchers at the Federal Institute for Materials Research and Testing (BAM) recently used automation techniques to turn impact echo into a scanning test method. This method produces an impact echogram, which is similar to a radargram. It can show the thickness of the concrete in detail, if dense measurement grids are used. If scanning is extended to a two-dimensional grid, it can even show results as a three-dimensional (3D) image [11].

Impact echo has advantages in that it is simple to perform and can locate large voids and delaminations. However, unless the recently developed scanning method is used, it does not generate an image and the results can be difficult to interpret [12].

\subsection{ACOUSTIC EMISSIONS}

Acoustic emission refers to the transient elastic waves that are generated by the release of energy in a material. This release of energy is primarily caused by microcracking, compression failure, yielding, fracture, or de-bonding between materials, but it can also be caused by sliding friction between interfaces [10]. When energy is released, acoustic waves travel through the material and are received 
by surface-mounted piezoelectric transducers. These transducers convert the acoustic waves to electric signals and a digital oscilloscope then captures the electric signals. The source of the acoustic emission can then be determined by calculating the difference in arrival times at the various transducers [3].

Acoustic emission monitoring could be quite useful since it can provide real-time feedback on the progression of damage, such as crack propagation. It is also a distributed sensing method that can cover an entire volume, as opposed to the more common point or line methods that cover only a small area. However, there are also several limitations. Acoustic emission monitoring is unable to tell the current state of the structure (existing cracks), only the change in state. Additionally, acoustic emissions have a high variability of signal strength, and background noise can have a significant effect on measurements. While qualitative analysis is well documented, it is quite difficult to perform a quantitative analysis in the field. Finally, there has been no long-term monitoring experience with this method [10].

\subsection{INFRARED THERMOGRAPHY}

Infrared thermography is a method of detecting internal flaws based on their effect on surface temperatures [3]. Internal defects disrupt the natural path of heat flow, causing temperature differences at the surface [11]. Since sound concrete should have a uniform temperature, these differences can be observed with an infrared camera to locate subsurface defects. The detectability of a defect depends on the heat capacity, heat conductivity, density, and emissivity of the object [3].

In order to use infrared thermography, heat must be flowing through the concrete. It does not matter which way the heat flows. Thermal energy is transferred from warmer to cooler regions in three ways: conduction, convection, and radiation. Sound concrete should have the least resistance to conduction, but negligible convection effects. Defects in concrete affect the flow of heat by decreasing conductivity without substantially increasing convection [3].

Infrared thermography has traditionally been a 2D sensing method, only giving information about the surface and unable to provide depth information. However, Sun [13] recently published a method of obtaining 3D data using a thermal tomography method. Sun's method first relates measurement time to the depth within the sample. It then expresses the thermal imaging data in the form of a material property and constructs a 3D spatial representation of the test sample. It should be noted that there is a considerable diffusion effect that causes image contrast to decrease with depth. However, this method could be quite useful in that 3D thermal effusivity data are somewhat similar to 3D x-ray CT data and can be sliced into planes.

Overall, infrared thermography seems like a promising method for locating problem areas. It has a major advantage in that it is an area testing technique, while most other NDE methods are point or line techniques [3]. Even if the thermal tomography method is not used, it would be a good method for scanning a large area provided there is heat flowing through it. 


\subsection{RADIOGRAPHIC TESTING}

Radiographic testing for concrete is similar to the type of radiography used in the medical community [14]. The two forms of radiographic testing, $\mathrm{x}$-rays and gamma rays, operate on the same basic set of principles. A beam of x-rays or gamma rays will experience a loss of intensity due to absorption and scattering as it passes through a concrete specimen. Radiation loss is dependent on the quality of the radiation source, the density of the material, and the thickness of the material. When the beam emerges, it is exposed to a radiation-sensitive film. Different intensities of radiation signify differing material densities, with darker areas typically indicating voids [3].

$\mathrm{X}$-rays and gamma rays differ in their sources of radiation. X-ray systems use a heated filament with a means of directing and accelerating electrons by means of a high-voltage supply, while gamma ray systems use radioisotopes [3].

Radiographic testing offers advantages in that it allows for visualization of density changes and also has a relatively deep penetration depth of slightly over $1 \mathrm{~m}$. However, it is not without its limitations. Radiographic testing is quite costly, and there are inherent safety concerns when dealing with radiation, which means licensed or certified personnel are a necessity. Additionally, this method requires access to both sides of the structure and does not provide information about thickness or depth to features [3] [5].

\subsection{ELECTROCHEMICAL TECHNIQUES}

Electrochemical techniques aim to detect corrosion in steel reinforcement, which is one of the most important forms of degradation to avoid. Corrosion occurs in two forms: general and pitting. General corrosion is caused by carbonation and occurs somewhat uniformly, while pitting corrosion is caused by chlorides and is a localized attack. It is important to note that electrochemical techniques cannot identify stress corrosion cracking since it is not an electrochemical process. Three techniques are commonly used to detect corrosion: half-cell potential, polarization resistance, and electrical resistivity measurements [15].

\subsubsection{Half-Cell Potential}

The half-cell potential technique involves measuring the voltage difference between the steel reinforcement and a reference electrode, or half-cell, in order to provide qualitative information on the steel's risk of corrosion [15]. Figure 4 shows a diagram of the typical testing equipment and setup [3]. The half-cell is typically a copper/copper sulfate or silver/silver chloride cell. Unfortunately, this method is not always completely nondestructive since it is sometimes necessary to drill into the concrete to expose the reinforcement. Additionally, this test can become complicated if the concrete is saturated with water or carbonated at the depth of the reinforcement. Steel coatings can also prove problematic [3] [15].

While the half-cell potential technique is useful in that it is quick to perform, it has several drawbacks. The most notable limitation is that it requires a physical connection to the reinforcing steel, which can require drilling. It also provides only relative readings and no quantitative information about the rate of corrosion. Finally, an experienced operator is generally required to interpret the results [3] [15]. 


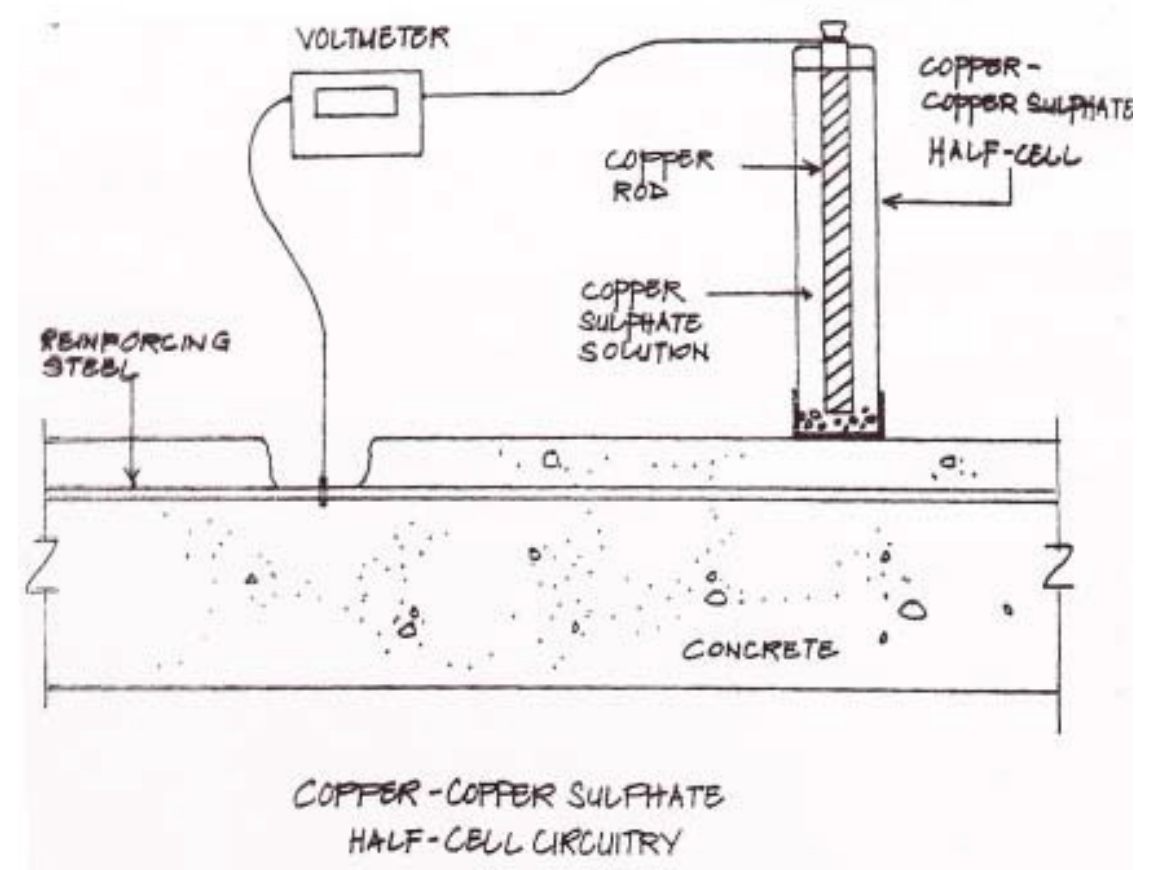

Figure 4. Half-cell potential testing equipment and setup [3].

\subsubsection{Polarization Resistance}

The polarization resistance method allows for the measurement of the instantaneous corrosion rate by quantifying the amount of metal per unit area being corroded at a particular instant. However, the evenly polarized area of metal surface must be known in order to calculate the instantaneous corrosion rate. This makes it quite difficult to apply to real size structures since the polarized area typically is not known. This method also requires direct connection to the steel reinforcement, which makes it not truly nondestructive [15].

\subsubsection{Electrical Resistivity Measurements}

The electrical resistivity measurement method is an indirect measurement of the concrete's porosity and the connectivity of the pores. This measurement can be used to detect wet areas in the concrete and provide information about the risk of corrosion. There are two methods of performing electrical resistivity measurements: the four point method and the disk, or one point, method [15].

The four point method uses four equally spaced electrodes at the surface of the concrete to measure the concrete's resistivity. Alternating current is passed through the outer two electrodes and the potential drop between the inner electrodes is measured. Direct connection to the reinforcing steel is not required [5] [15].

The disk, or one point, method measures the concrete's resistivity based on an estimation of the ohmic drop between the steel reinforcement and a disk placed at the surface of the concrete. This method does require direct contact to the steel reinforcement [15]. 


\subsection{SUMMARY OF CURRENT NDE CONCRETE MEASUREMENT TECHNIQUES}

Table 1 below summarizes the current NDE techniques for measuring concrete degradation.

Table 1. Summary of current NDE concrete measurement techniques

\begin{tabular}{|c|c|c|}
\hline NDE Method & Advantages & Disadvantages \\
\hline Visual Inspection & Simple, fast & Relies on experience \\
\hline Ground-Penetrating Radar & $\begin{array}{l}\text { Rapid; non-contact; can obtain depth } \\
\text { and thickness measurements; good at } \\
\text { locating embedded metals }\end{array}$ & $\begin{array}{l}\text { Limited depth of penetration } \\
(0.6 \mathrm{~m}) \text {; subjective to data } \\
\text { interpretation; cannot see behind } \\
\text { metal }\end{array}$ \\
\hline Ultrasonic - general & $\begin{array}{l}\text { Thickness measurement; embedded } \\
\text { metal location; imaging capability }\end{array}$ & $\begin{array}{l}\text { See below different ultrasonic } \\
\text { techniques }\end{array}$ \\
\hline Ultrasonic Pulse Velocity & $\begin{array}{l}\text { Can be one-sided measurement } \\
\text { (indirect transmission); void/defect } \\
\text { location; simple }\end{array}$ & Requires transmitter and receiver \\
\hline Ultrasonic Pulse Echo & $\begin{array}{l}\text { Single transducer; can be multi- } \\
\text { sensor array }\end{array}$ & $\begin{array}{l}\text { Speed of sound in concrete being } \\
\text { tested must be measured }\end{array}$ \\
\hline $\begin{array}{l}\text { Ultrasonic Coda Wave } \\
\text { Interferometry }\end{array}$ & $\begin{array}{l}\text { Quite useful for detecting changes } \\
\text { and monitoring damage }\end{array}$ & $\begin{array}{l}\text { Does not appear to located defects; } \\
\text { requires high signal-to-noise ratio } \\
\text { in the field }\end{array}$ \\
\hline Impact Echo & $\begin{array}{l}\text { Simple; can locate large voids and } \\
\text { delaminations in plate }\end{array}$ & Results can be difficult to interpret \\
\hline Acoustic Emissions & $\begin{array}{l}\text { Can provide real-time feedback on } \\
\text { crack propagation }\end{array}$ & $\begin{array}{l}\text { Can only detect change in state; } \\
\text { high variability in signal strength; } \\
\text { background noise can have } \\
\text { sufficient effect on the } \\
\text { measurement }\end{array}$ \\
\hline Infrared Thermography & $\begin{array}{l}\text { Area testing technique; good for } \\
\text { finding voids }\end{array}$ & $\begin{array}{l}\text { Requires a thermal gradient } \\
\text { through the concrete }\end{array}$ \\
\hline Radiographic & $\begin{array}{l}\text { Deep penetration; visualization of } \\
\text { density changes }\end{array}$ & $\begin{array}{l}\text { Requires access to both sides of the } \\
\text { concrete being tested; costly; } \\
\text { safety concerns }\end{array}$ \\
\hline Half-Cell Potential & $\begin{array}{l}\text { quick; simple; qualitative } \\
\text { information on steel rebar risk of } \\
\text { corrosion }\end{array}$ & $\begin{array}{l}\text { Relative readings; subjective to } \\
\text { data interpretation; rebar being } \\
\text { tested must be exposed; steel } \\
\text { coatings can be problematic; } \\
\text { complicated if saturated with water }\end{array}$ \\
\hline Polarization Resistance & $\begin{array}{l}\text { Measures instantaneous metal } \\
\text { corrosion rate }\end{array}$ & $\begin{array}{l}\text { Polarized area of metal surface } \\
\text { being tested must be known; } \\
\text { requires direct connection to metal }\end{array}$ \\
\hline Electrical Resistivity & $\begin{array}{l}\text { Indirect measurement of concrete's } \\
\text { porosity and the connectivity of } \\
\text { pores; can be used to detect wet areas } \\
\text { in concrete; measures resistivity }\end{array}$ & $\begin{array}{l}\text { One point method requires direct } \\
\text { connection to rebar }\end{array}$ \\
\hline
\end{tabular}




\section{WORKSHOP R\&D ACTION LIST}

The LWRS NDE concrete workshop participants were introduced to the challenges and complexity associated with making thick concrete measurements in NPPs and the current concrete NDE technologies, which have been outlined in the first eight sections of this roadmap report. After this initial review (through presentations by invited experts), the participants were given 30 minutes to define what they thought were the most pressing R\&D actions to address gaps between available concrete NDE measurement techniques and the technology needed to make these measurements on our current NPP fleet. These R\&D Action inputs where categorized, and the participants were broken up into three working groups. The results of this work are the prioritized R\&D Actions listed below.

\subsection{NEED TO SURVEY AVILABILITY OF CONCRETE NDE SAMPLES}

For the studies planned for this project, adequate test blocks/samples play a key role, since they can provide defined conditions under which the different NDE concrete measurement methods can be evaluated. Material properties as well as the location of reinforcement, tendon ducts, and test flaws have to be well documented. The blocks can be field removed or artificially made. Field-removed test blocks naturally provide the most realistic simulation of the testing problem, especially those removed from NPPs with heavily reinforced steel and have been exposed to high temperature and radiation exposure. The artificial blocks can provide more defined conditions, since the critical parameters can be controlled during the block fabrication.

Test blocks need to reflect the testing problem as realistically as possible in regards to the test method applied to them. Test flaws should be as similar as possible to actual flaws in terms of how they interact with the particular test method, while at the same time the way they are generated does not necessarily have to be the same mechanism that would cause such a flaw in the field.

Artificial test blocks allow the isolation of certain testing problems as well as the variation of certain parameters. Because of the controlled conditions in the laboratory, the number of unknown variables can be decreased, which makes it possible to focus on specific aspects, investigate them in detail, and gain further information on the capabilities and limitations of the methods. However, the materials used for the fabrication of the artificial test blocks may not be representative of the original concrete fabricated some 40 to 50 years ago: old cements being usually coarser than nowadays cement. Fine cements set and hydrate, generating a high heat release at the early age that can cause thermal cracking and potentially delayed ettringite formation if not cured correctly. The original admixture (plasticizer, etc.) may not be available anymore.

Furthermore, a detailed documentation and testing program must be tied to the construction of any new artificial test blocks. It should include the following.

- Detailed drawings of the position of steel elements and other inclusions

- Augmented monitoring including (to be defined depending on the type of degradation studied) temperature, moisture content, strain (local/structural scale), resistivity, etc.

- Thorough quality control of the placement of the embedded elements: steel reinforcement/post-tensioning system, sensors and "prefabricated" flaws (voids, inclusions, plates, etc.)

- Significant material testing of concrete properties at different ages (to be defined depending on the type of degradation studied) including mechanical properties (strength, elasticity, shrinkage, etc.), durability-related properties (porosity, permeability, diffusions coefficients, etc.); additional control samples might also be required 
To minimize artifacts caused by boundary effects, the dimensions of the specimens should not be too compact. The exact size will depend on the NDE method used. There are practical limitations since such blocks are placed in laboratories and in most cases will have to be movable. As a compromise, a size of approximately $2.00 \mathrm{~m}$ by $1.50 \mathrm{~m}$ and a thickness depending on the particular testing problem have proven to be practical.

\subsubsection{Available Samples}

\section{Florida Department of Transportation (FDOT), Gainesville, Florida}

The Florida Department of Transportation initiated an NDE validation facility at their State Materials Office in Gainesville, Florida, in 2009. Test blocks simulating the various testing problems were given a high priority here. Various artificial blocks were fabricated addressing the following testing problems.

- Thickness measurements (block varying in thickness)

- Rebar detection/measuring concrete cover (block with multiple layers of reinforcement, varying in depth, rebar diameter and spacing)

- Tendon duct inspection (several blocks with metal ducts; the different duct sections are fully grouted, partially grouted, or ungrouted). There are ducts of different diameters, at different depths with different spacing, additional reinforcement above the duct, etc.

- Determination of physical properties (solid block, also used as a reference for results obtained from other blocks)

All blocks have dimensions of approximately $2.00 \mathrm{~m}$ by $1.50 \mathrm{~m}$ or larger and are brought into an automated test frame for inspection (Figure 5).

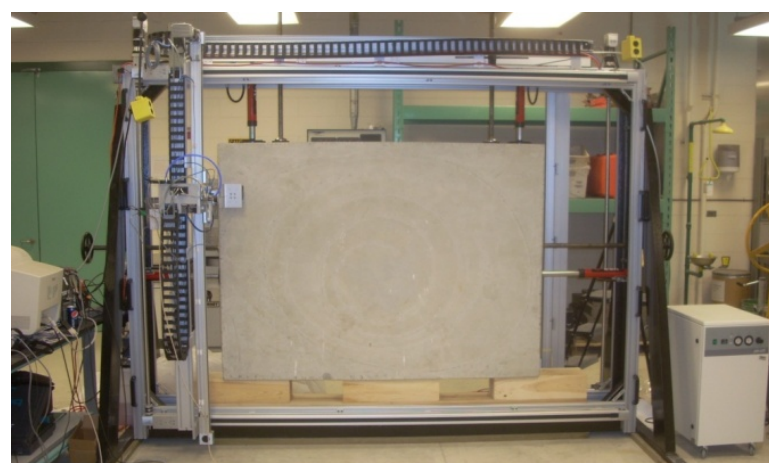

Figure 5. Test block in the automated NDE test frame.

\footnotetext{
Federal Highway Administration (FHWA) NDE Validation Center in McLean, Virginia

The FHWA NDE Validation Center (NDEVC) focuses on the evaluation of the reliability of NDE methods in regards to bridge inspections. There is a variety of field-removed test blocks, including more than a dozen reinforced concrete deck sections, each approximately $1.8 \mathrm{~m}$ by $3.8 \mathrm{~m}$. These panels have been removed from bridges undergoing rehabilitation and contain defects and deterioration typical of structurally deficient bridge decks.
} 
In addition, NDEVC has an extensive collection of fatigue-crack specimens. These specimens contain a variety of types and sizes of flaws and can be used to investigate a wide range of NDE techniques [16].

\section{Federal Institute for Materials Research and Testing (BAM) in Berlin (Germany)}

The Federal Institute for Materials Research and Testing (BAM) is located in Berlin (Germany). BAM has accomplished major achievements in research and development in regards to NDE of concrete structures. There is a great variety of mostly artificial but also field-removed test blocks addressing various testing problems. Other large-scale test blocks are located at their secondary test site in Horstwalde (Germany), outside of Berlin.

\section{Decommissioned Nuclear Power Plant Concrete Samples}

Typically, concrete samples collected on decommissioned NPPs are small-area core samples. As NPPs are decommissioned here in the United States and abroad, it would be advantageous as part of the decommissioning process to strategically retain and document large concrete samples for use in validating and testing the various NDE concrete measurement techniques.

\subsection{NEED A TECHNIQUE TO PERFORM VOLUMETRIC IMAGING ON THICK REINFORCED CONCRETE SECTIONS}

Imaging of the volume of thick structures has been identified as a highly relevant necessity and would be very useful to NPP managers. A picture says more than a thousand waveforms - with that said, massive and heavily reinforced NPP concrete structures provide challenges to internal imaging with NDE methods. Higher energy is required to provide deeper wave penetration into the concrete, and it is difficult to detect small defects throughout the large volume. The heavily reinforced structures create a "shadow zone" beneath which the wave energy cannot penetrate and thus make it impossible to inspect the volume behind it.

Imaging can significantly enhance the interpretability of the outcome of NDE. The overall goal is to obtain images that provide all relevant information on the volume of the structure. The features shown in the visualization obtained can include the structural components themselves depicted at their located position or degraded areas and volumes within the structure that require special attention. These can be delaminated areas such as cavities or honeycombs, low concrete covering of reinforcement steel, or areas with different physical properties.

With further development and improvements, there are several techniques that are promising in the ability to image concrete structures.

\subsubsection{Ground-Penetrating Radar}

GPR has many applications in a number of fields and engineering applications include NDE of structures and pavements. As an electromagnetic method, it is very sensitive to metallic reflectors in the concrete (e.g., reinforcement, metal tendon ducts, and anchors). An antenna transmits and receives electromagnetic waves that are reflected at interfaces between layers with different dielectric properties, such as the interface between the concrete and reinforcing steel, voids, or defects. This makes the method very capable of detecting metallic reflectors such as reinforcing steel, metal ducts, or other metallic structural components inside the volume, as well as voids and defects.

The penetration depth as well as the resolution of the measurement depends on the wavelength of the 
transmitted wave and therefore the specific frequency of the respective antenna. A higher frequency will provide better resolution but will also result in lower penetration depth, whereas use of a lower frequency increases the penetration depth but limits the resolution. The choice of the antenna to be used will also highly depend on the reinforcement density. Dense reinforcement along the surface of a structure will cause full reflection of the wave if the wavelength is too large, thus making it impossible to inspect the volume behind it. Therefore, dense reinforcement at the surface of a structure will require a relatively small wavelength and high frequency, which again limits the overall penetration depth, so that a compromise needs to be made. However, if the structure to be inspected is thick, the applicability of GPR will depend on the reinforcement density.

GPR is capable of being a rapid, non-contact method of obtaining depth and thickness measurements and is very sensitive to embedded metals. It is a well-established measurement method and with further development may overcome some of its limitations as to depth penetration. The interpretation of the data can be quite subjective, but this too may be overcome with appropriate signal processing algorithms.

\subsubsection{Ultrasound}

Ultrasonic testing methods have a wide range of applications including thickness measurement, locating steel reinforcement and tendon ducts, and characterization of surface cracks. It also shows promise for investigating grouting conditions inside grouted tendon ducts. Unlike electromagnetic waves, acoustic waves are capable of penetrating metal components such as liners [6].

Concrete is a multiphase, heterogeneous, multiple-length-scale material consisting of a cement-paste matrix plus fine (sand) and coarse (gravel) aggregates. The heterogeneities in concrete such as the random distribution of aggregate in the cement-paste matrix lead to strong scattering of ultrasonic waves at wavelengths on the order of the aggregate. Use of relatively high ultrasonic frequencies, typically in the high $\mathrm{kHz}$ to low $\mathrm{MHz}$ range, is necessary to detect damage at an early stage. The ultrasound energy density in this regime can be described by the diffusion equation. Research has developed a quantitative understanding of the effects of additional scattering sources, such as microcracks in the cement-paste matrix due to alkali-silica reaction (ASR), on the diffusion and the dissipation coefficients. Other research has applied diffuse ultrasound to determine the depth of surface-breaking cracks in concrete specimens, while others have examined the effect of microstructure on the diffuse ultrasound field and shown that the dissipation coefficient is directly related to the amount of viscoelastic cement-paste matrix in a specimen.

Promising advanced ultrasonic techniques to characterize damage in concrete include both diffuse and nonlinear methods. Many forms of ultrasonic testing exist, but the most promising for NPP applications are pulse echo, impact echo, coda wave interferometry and other nonlinear techniques.

\section{$\underline{\text { Pulse Echo }}$}

Ultrasonic echo is widely used nowadays for NDE of concrete structures. It uses the same impulse echo principle as radar. Ultrasonic waves are reflected at interfaces where acoustic impedance differs, and the propagation time to the interface and back can be measured to learn about the interior of the structure. This method is a bit more flexible than ultrasonic pulse velocity because it only requires a transducer that both transmits and receives. This means it also only requires access to one side of the structure, which is ideal for NPP NDE. 
The development of devices using dry-coupled ultrasonic probes (Figure 6) has made the method very practical for its application on concrete surfaces. Especially in combination with the SAFT (Synthetic Aperture Focusing Technique) algorithm [17] [18], this method is highly suitable for imaging of the inner volume of a structure and detection of volumetric or planar reflectors.

Compared to GPR, ultrasonic echo is an acoustic method and therefore is sensitive to interfaces between layers of different elastic properties. This makes it possible to penetrate metal layers and inspect the volume behind them, whereas an electromagnetic wave as used in GPR would be fully reflected at the metal interface. This becomes relevant for example for the inspection of tendon ducts in post-tensioned structures.

As demonstrated in previous studies (e.g., [19] [20] [21] ), ultrasonic echo is capable of detecting and locating reinforcement steel in multiple layers, as long as the measurements are conducted along a dense grid.

Ultrasonic pulse echo has also been successfully applied for detection of honeycombs. The honeycombed area can be detected mostly through a drop in amplitude, which is caused by diffuse scattering of the wave by the honeycomb. Therefore, measurements need to be conducted along scan lines, so that the amplitude drop becomes apparent by comparing the amplitudes obtained along the scan line. This becomes clearly visible through the imaging.

Generally, ultrasonic pulse echo is well suited for detection of planar flaws parallel to the coupling surface inside the structure.
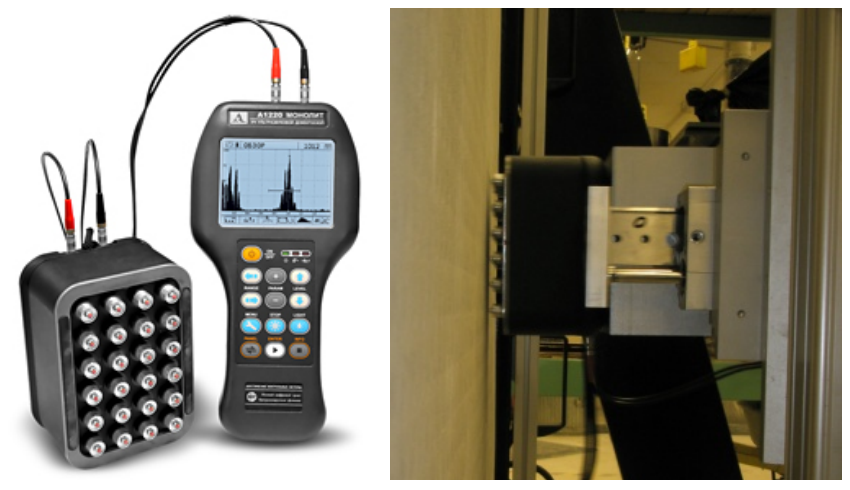

Figure 6. Ultrasonic Sensor. Dry-coupled sensor with at center frequency of $55 \mathrm{kHz}$, designed for measurements on concrete. Left: Probe with handheld controller. Right: Probe mounted on scanning system for automated use.

\section{Impact Echo}

Impact echo is similar to the pulse echo technique and has been successfully applied for thickness measurements and for the localization of defects inside concrete structures. Its principle is based on the analysis of multiple reflections after mechanical impact excitation [22]. A small steel ball or hammer is tapped on the surface of a concrete structure and creates stress waves propagating through the material. The multiple reflections are analyzed in the frequency spectrum using the Fast Fourier Transform (FFT). There is a direct relationship between the measured frequency $f$ and the depth $d$ of a reflector:

$$
2 d=c_{L} \cdot T=\frac{c_{L}}{f} \quad \Leftrightarrow \quad d=\frac{c}{2 f}
$$


Its application as a scanning method in combination with imaging techniques has significantly improved the possibilities of the method [23]. See Figure 7 below.
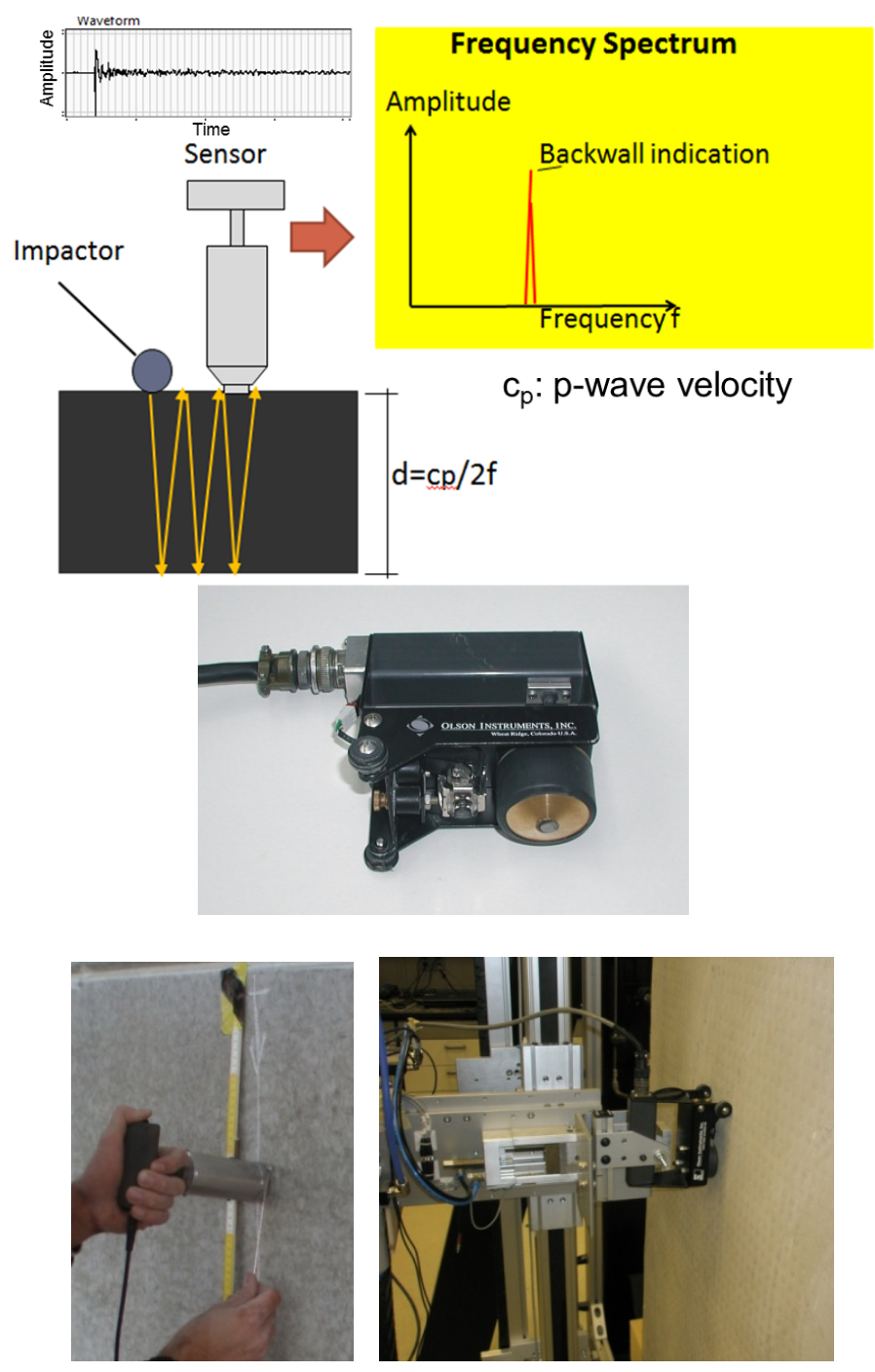

Figure 7. Impact Echo. Top: Principle of impact echo. Left: Automated impact echo probe. Center: Manual application of impact echo. Right: Sensor head mounted on scanning system.

Since ultrasonic pulse echo is generally more sensitive in regards to volumetric reflectors (flaw detection), impact echo is mostly used for the detection of shallow delamination. Due to generally larger wavelengths compared to those of ultrasonic pulse echo, it is hardly affected by reinforcing steel even in highly reinforced structures. The frequency content of the pulse and the resultant wavelength of the wave depend mostly on the size of the impactor (diameter of the steel ball). Larger wavelengths and therefore higher penetration depths can be achieved by using larger impactor diameters. However, larger wavelengths will also reduce the sensitivity of the method to reflectors inside the volume of the structure. 
Recent developments using microphones as sensors for contactless measurements show promising results [2] [24] [25] [26] [27]. This can expedite the measurement process significantly since the sensor does not need to be lifted up between the measurement positions but can be moved continuously along the measurement surface. It has the potential to increase the speed at which measurements can be taken, compared to the speeds of conventional impact echo and ultrasonic pulse echo techniques. See Figure 8 and Figure 9 below.

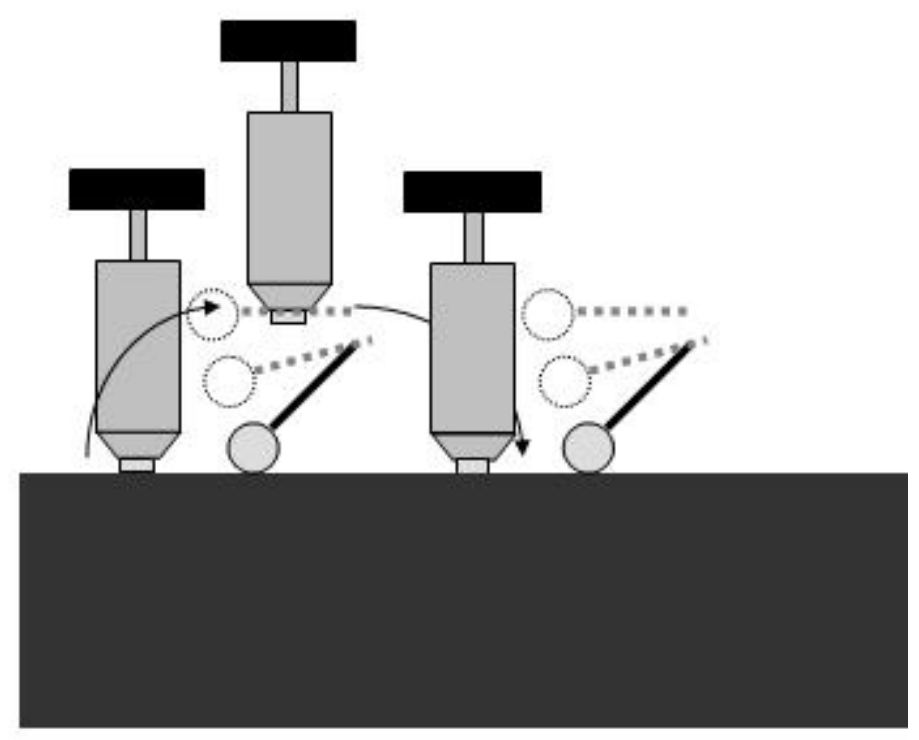

Figure 8. Time-consuming scanning using conventional contact sensors. The sensor needs to be raised between the measurement positions and coupled to the surface.

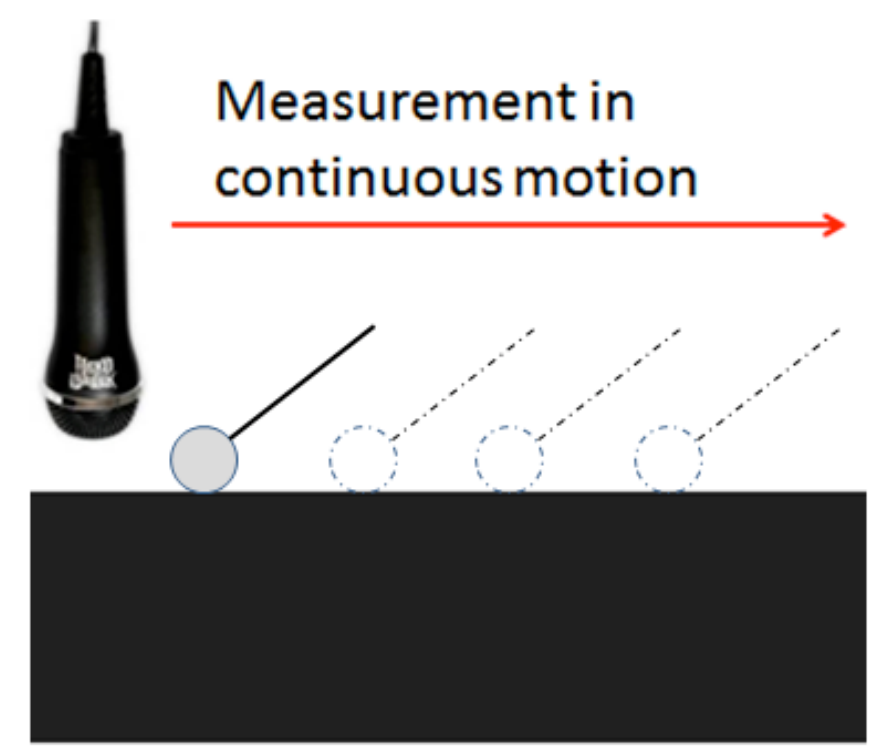

Figure 9. Goal: measurement in continuous motion using a microphone. 


\section{Coda Wave Interferometry}

Coda wave interferometry (CWI) is a technique that allows one to observe differences in the coda portion of a diffuse field. When an ultrasonic wave is emitted into a concrete specimen, the heterogeneous nature of the concrete causes the wave to become highly scattered, and a diffuse field is created. A diffuse field consists of two parts: the first arrival wave and the later arrival wave or the diffuse portion, which includes the late coda contribution. Diffuse waves undergo multiple scattering, which causes them to arrive much later than the first arrival. However, diffuse waves are much more sensitive to small changes in the concrete medium and carry more information than the first arrival [11]. Their signal contains rich information about the medium and, efforts have been made to develop techniques to systematically extract useful information from diffuse coda waves.

In an ultrasonic CWI measurement, by launching ultrasonic waves and comparing two coda waves measured at different conditions (e.g., at different stress levels), the relative changes in wave velocity can be extracted. The velocity changes may be caused by damage and/or microstructure modifications in the medium at the wavelength scale. Recently, researchers have applied the CWI technique to concrete samples and demonstrated high accuracy of their experimental method in measuring the stress-dependent velocity changes in concrete. Others have observed that velocity changes in concrete are about ten times higher than those in metals and have quantified concrete damage due to thermal shock and mechanical cyclic loading.

There are two types of CWI: the doublet technique and the stretching technique. The stretching technique is the more advanced of the two and is more commonly used. This technique is performed by scaling the time access so as to stretch a waveform. The time axis is stretched or compressed until it has much in common with a reference time signal. Since time and velocity are proportional, the relative velocity can be calculated from the scaling factor [11].

CWI appears to be quite useful for detecting changes and monitoring the progression of damage in concrete. However, it does not seem to be able to locate defects. It also requires a high signal-to-noise ratio to be effective in the field [11].

\section{Nonlinear}

Nonlinear ultrasonic and acoustic methods for characterizing materials show considerable promise in detecting damage in concrete. These nonlinear techniques have proven to be more sensitive to damage than the traditional linear ultrasonic measurements. Methods such as nonlinear resonance ultrasound spectroscopy (NRUS) have been applied to concrete with thermal damage, as well as other hysteretic materials with mechanical damage. In addition, the nonlinear reverberation spectroscopy (NRS) technique that uses free nonlinear vibration responses of the specimen after turning off a long harmonic excitation has been applied to damage detection in reinforced concrete slab and laminate composite specimens. With respect to damage associated with ASR, the nonlinear wave modulation spectroscopy (NWMS) and nonlinear impact resonance spectroscopy (NIRAS) technique have shown potential for earlier damage detection than traditional testing procedures. In contrast to NRUS, where a swept sine excitation is used, NIRAS relies on impulse excitation of a specimen and measurement of the free vibration response. Note also that NIRAS is different from NRUS in the data processing procedure and the instrumentation method, which are much simpler than those of NRUS.

Current research is using the second harmonic generation and collinear mixing to measure the nonlinearity of concrete. For example, Rayleigh surface wave propagation is being used to detect and characterize the carbonation depth in concrete. Nonlinear ultrasonics, shown in Figure 10, is being 
used to measure the material nonlinearity of a propagating Raleigh wave, which can be directly related to the presence of a carbonated layer. By varying the propagation frequency of these Rayleigh waves, it should be possible to measure the penetration depth of the carbonation layer. This approach was taken to measure the depth of residual stress in shot peened aluminum specimens.

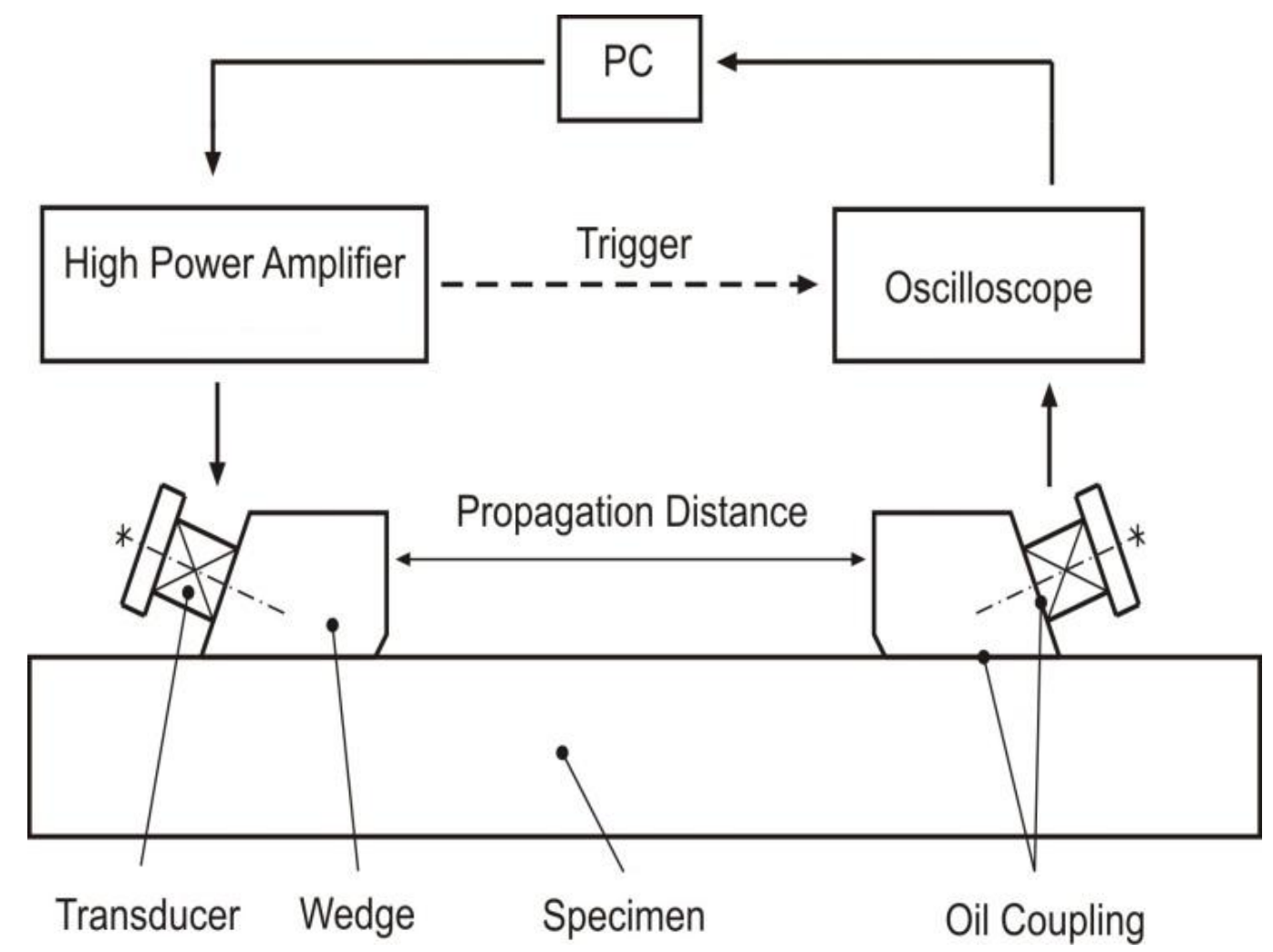

Figure 10. Nonlinear ultrasonic schematic.

\subsubsection{Radiographic [3]}

The intensity of a beam of x-rays or gamma rays suffers a loss of intensity while passing through a material. This phenomenon is due to the absorption or scattering of the $\mathrm{x}$-rays or gamma rays by the object being exposed. The amount of radiation lost depends on the quality of radiation, the density of the material, and the thickness traversed. The beam of radiation, which emerges from the material, is usually used to expose a radiation-sensitive film so that different intensities of radiation are revealed as different densities on the film.

Unlike most metallic materials, reinforced concrete is a nonhomogeneous material, a composite with low-density matrix, a mixture of cement, sand, aggregate and water, and high-density reinforcement, made up of steel bars or tendons. Radiography can therefore be used to locate the position of reinforcement bars in reinforced concrete, and also estimates can be made of bar diameter and depth below the surface. It can reveal the presence of voids, cracks, and foreign materials, the presence or absence of grouting in post-tensioned construction, and variations in the density of the concrete. 
Gamma-ray sources are usually used for concrete thickness up to about $500 \mathrm{~mm}$. Above $500 \mathrm{~mm}$ the use of high-energy x-rays is more appropriate (Table 2). When a metal liner is adhered to the inner wall of concrete, the energy needed should be considered carefully.

Table 2. Sources of radiation for different concrete thicknesses [3]

\begin{tabular}{|c|c|c|}
\hline Source & \multicolumn{2}{|c|}{ Approximate concrete thickness } \\
\hline & Minimum & Maximum \\
\hline Co-60 & $125 \mathrm{~mm}$ & $500 \mathrm{~mm}$ \\
\hline Ir-192 & $25 \mathrm{~mm}$ & $250 \mathrm{~mm}$ \\
\hline Linac, $18 \mathrm{MeV}$ x-rays & $500 \mathrm{~mm}$ & $1600 \mathrm{~mm}$ \\
\hline
\end{tabular}

The main limitation of radiography is that high-energy radiation is required to penetrate thick sections of concrete and both sides have to be accessed. In addition this technique does not provide information about thickness or depth to features. If $\mathrm{x}$-ray equipment is to be used, it can be very heavy and therefore difficult and time-consuming to set up in the field. Because the focus to film distance may have to be long, the exposure time is also long so that the cost of radiography can be high. The other limitation is that if there is a high density of radiation inside of the concrete nuclear containment, the film will be polluted in the test.

\subsection{NEED TECHNIQUES TO DETERMINE PHYSICAL AND CHEMICAL PROPERTIES AS A FUNCTION OF DEPTH}

Knowledge on the physical properties of a concrete structure provides highly relevant information on its structural condition. Many concrete degradation mechanisms are driven by environmental exposures (temperature, moisture, radiation, etc.) that are concentrated at the exposed surface. As a result, degradation mechanisms can form damage gradients with respect to depth, and it is important to characterize this degradation (which manifests as material softening and porosity increases) both in terms of damage extent and depth. Existing NDE methods do not provide sufficient performance for this task for concrete NPP structures, but some existing methods do hold promise with further development. For example, traditional linear ultrasonic surface wave methods have been used to characterize large-scale layered gradient structures such as pavements. Elastic properties can be determined based on the relationship between longitudinal and shear wave velocity of ultrasonic waves, as shown in Figure 11 below.

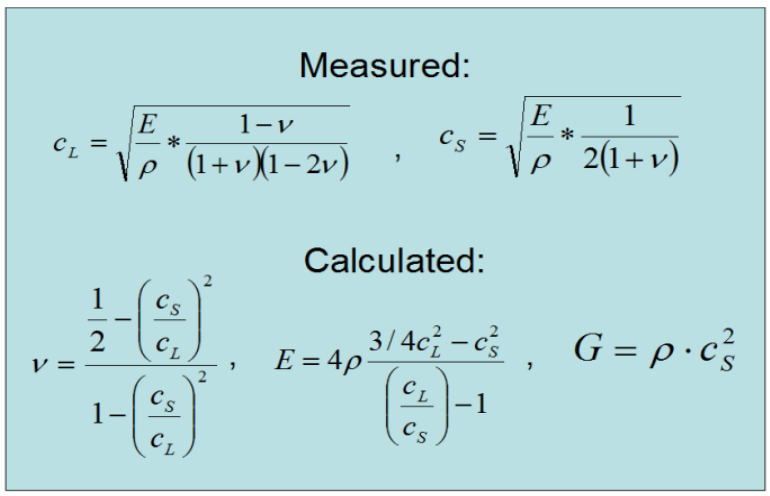

Figure 11. Elastic properties from logitudinal and shear ultrasonic waves and density.

For determining the modulus of elasticity, the density has to be known. The density can be determined based on samples. Rough estimation of the density will limit the accuracy with which the 
modulus of elasticity can be determined. Based on the same equation, the density can be calculated if the modulus of elasticity is known.

To determine the physical properties as a function of depth, the wave velocities (longitudinal and shear) will have to be determined as a function of depth too. This can be achieved by ultrasonic measurements in a multistatic transmission (tomographic) setup and application of inversion algorithms.

These methods can be modified and improved to address the damage gradient problem. For example, advanced reconstruction algorithms from the geophysics communities can be deployed for this case. Also new developments, such as nonlinear ultrasonic behavior and "coda wave" interpretation, could potentially be used to enhance the performance of surface wave methods.

\subsection{NEED TECHNIQUES TO DETERMINE INTERFACES BETWEEN CONCRETE AND OTHER MATERIALS}

NPP concrete structures often contain significant interfaces between different material constituents. For example, concrete containment structures typically contain an interior steel sheet liner covered in a massive concrete layer. It is difficult to inspect the integrity of the steel liner, which is critical for containment performance, using NDE methods from the exterior concrete surface. However, seismic wave methods that have been developed and deployed on the geophysical community for deep inspection of geologic strata; these methods can be modified and improved to address the deeply embedded interface problem. For example, advanced reconstruction algorithms from multi-element seismic arrays could be developed and deployed for this case. Similarly, local vibration monitoring methods (similar to impact echo) could be deployed to locate changes in liner bonding within the dome.

In other cases the concrete is not directly accessible but covered by a steel liner, so that the concrete needs to be inspected through the steel liner, which makes the inspection quite challenging.

So far, there are no methods that are designed for inspection of concrete through steel. GPR cannot be applied in such cases, since the electromagnetic waves would be reflected completely by the steel layer, thus making it impossible to reach the inspection volume behind the steel.

Ultrasonics could generally be applied in such cases. However, the probes for concrete inspections are designed to be coupled on the concrete surface and not on an additional steel layer. As long as the steel layer is fully bonded with the concrete, it will be possible to apply ultrasonics. However, if the steel debonds from the concrete due to shrinkage of the concrete, an ultrasonic wave will be reflected almost completely at the steel/air interface, thus making it impossible to reach the concrete.

Since impact echo is also an acoustic method, it will generally suffer the same limitation as ultrasonics in this case, due to its inability to overcome the steel/air interface and reach the concrete behind it, when the steel is no longer bonded to the concrete. Furthermore, it is not clear what effect the steel cover would have on impact echo measurements, even when the steel is perfectly bonded to the concrete.

\subsection{NEED TO DEVELOP ACCEPTANCE CRITERIA - MODELING AND VALIDATION}

To make development of NDE methods efficient, the necessary metrics should be specified and bound. This leads to the question of the acceptance criteria for the respective concrete structures. For example, what is the smallest flaw size that needs to be detected? What is the largest flaw size that 
can be missed without harm? How accurate does the wall thickness need to be known? With what accuracy do physical parameters need to be determined? What percentage of the entire volume of the structure needs to be inspected? And finally using the above metrics and boundaries, determine if the concrete structure is "good enough."

Such information can be obtained for example from finite-element analyses studying the effect that flaws of different sizes or changes in the physical properties of a certain amount would have on the structure.

In addition, the NDE and NPP management community needs deeper scientific understanding of concrete degradation mechanisms expected in NPP structures. For example, scientists and engineers need to better understand the effects of sustained temperature and radiation exposure on the mechanical properties of concrete, at the material microstructural level, and then examine the effects of these changes on the phenomena used in NDE methods, such as mechanical wave propagation. In this way, the microstructural degradation mechanisms can be characterized in a model, and then interpreted through the resulting NDE results.

\subsection{NEED FOR AUTOMATED SCANNING SYSTEMS}

Due to the massive concrete areas requiring NDE measurements in NPPs, an automated scanning measurement system for any of the NDE techniques is almost a requirement. Large areas and volumes require lots of measurements for mapping concrete deformations. The resolution and quality of the images obtained is given by the density of the scan grid and the position accuracy of the measurements. This makes the application of automated scanners very relevant. Automating the scanning of the measurement system will have many benefits, such as the following.

- Improved measurement accuracy

- Improved measurement repeatability

- Precise coordinates can be made with measurement

- Reduction of human errors in the measurement

- Safer operation with less human involvement

- Speed of mapping greatly increased

- Large number of measurements can be made

For the above reasons, automated scanners for NPP NDE concrete measurements are greatly desired. 


\section{CONCLUSIONS}

Concrete-based structures perform many important functions as part of a typical LWR plant by providing a foundation, support, shielding, and containment functions. Many concrete structures such as the containment building, spent fuel pool, and cooling towers are important to the safety of LWR plants. Ensuring the long-term performance of these concrete structures is essential for the safe operation of commercial NPPs.

Age-related degradation may affect engineering properties, structural resistance/capacity, failure mode, and location of failure initiation that in turn may affect the ability of a structure to withstand challenges in service. In order to ensure the safe operation of NPPs, it is essential that the effects of potential degradation of the plant structures, as well as systems and components, be assessed and managed during both the current operating license period as well as subsequent license renewal periods. In contrast to many mechanical and electrical components, replacement of many concrete structures is impractical.

Due to the complex nonhomogeneous nature of NPP concrete structures, existing NDE techniques typically do not provide sufficient confirmation that the structures can perform adequately. Additionally NPP concrete structures are often inaccessible and contain large volumes of massively thick concrete. These structures are exposed to a variety of environments and a diversity of degradation mechanisms (high temperatures, radiation exposure, chemical reactions) at various locations throughout the commercial NPP. All these factors add to the complexity of determining the integrity and quality of the concrete.

This report has identified several important R\&D tasks.

1) Need to survey available samples

Comparative testing on the various NDE concrete measurement techniques will require concrete samples with known material properties, voids, internal microstructure flaws, and reinforcement locations. These samples can be artificially created under laboratory conditions where the various properties can be controlled. In addition concrete samples that have been removed from the field and exposed to known aging mechanisms (different levels of radiation/temperature/chemical reaction) provide the most realistic concrete aging specimens.

2) Technique(s) to perform volumetric imaging on thick reinforced concrete sections A technique or a combination of techniques that could reliably and quickly generate an image of the volume of thick concrete structures will significantly enhance the interpretability of the outcome of the various NDE measurement methodologies and is greatly desired.

3) Determine physical and chemical properties as a function of depth

Knowledge on the physical and chemical properties of a concrete structure, especially as a function of depth, will provide highly relevant information on its structural integrity.

4) Techniques to examine interfaces between concrete and other materials

In some cases, the structural concrete to be inspected is covered by a steel liner. Presently there are no techniques designed for inspecting concrete through steel.

5) Development of acceptance criteria - model and validation

Through modeling and validation, an acceptance criterion needs to be developed to determine that a concrete structure is "good enough." For each NDE concrete measurement metric (void 
size, crack size, reinforcement degradation, physical properties), an upper and lower acceptance boundary needs to be determined.

6) Need for automated scanning systems

Due to the massive concrete areas requiring NDE measurements in NPPs, an automated scanning measurement system for any of the NDE techniques is almost a requirement. Large areas and volumes require lots of measurements for mapping concrete deformations. The resolution and quality of the images obtained are determined by the density of the scan grid and the position accuracy of the measurements. This makes the application of automated scanners very relevant and greatly desired.

All of the above R\&D tasks are very important in order to solve the complex issues associated with making NDE concrete measurements in NPPs to verify the integrity and quality of the concrete.

Table 3 summarizes the priority, minimum duration, funding required for the minimum duration, the total level of effort in full-time equivalents (FTEs), and the total cost for each of the six identified projects.

Table 3. Summary of Projects

\begin{tabular}{|c|l|c|c|c|c|}
\hline $\begin{array}{c}\text { Task } \\
\text { ID }\end{array}$ & \multicolumn{1}{|c|}{ Projects } & Priority & $\begin{array}{c}\text { Min. Duration/ } \\
\text { Funding } \\
\text { Required }\end{array}$ & $\begin{array}{c}\text { Level of } \\
\text { Effort } \\
\text { (Total) }\end{array}$ & $\begin{array}{c}\text { Total } \\
\text { Costs }\end{array}$ \\
\hline \hline 1 & $\begin{array}{l}\text { Survey Available } \\
\text { Samples }\end{array}$ & High & $\begin{array}{c}1 \text { Year } \\
\$ 125 \mathrm{~K} / \mathrm{yr}\end{array}$ & $0.5 \mathrm{FTE}$ & $\$ 125 \mathrm{~K}$ \\
\hline 2 & $\begin{array}{l}\text { Volumetric } \\
\text { Imaging of Thick } \\
\text { Sections }\end{array}$ & $\begin{array}{l}\text { Very } \\
\text { High }\end{array}$ & $\begin{array}{c}4 \mathrm{Years} \\
\$ 900 \mathrm{~K} / \mathrm{yr}\end{array}$ & $12 \mathrm{FTEs}$ & $\$ 3.5 \mathrm{M}$ \\
\hline 3 & $\begin{array}{l}\text { Physical and } \\
\text { Chemical } \\
\text { Properties as a } \\
\text { Function of Depth }\end{array}$ & High & $\begin{array}{c}4 \text { Years } \\
\$ 1.2 \mathrm{M} / \mathrm{yr}\end{array}$ & $16 \mathrm{FTEs}$ & $\$ 4.6 \mathrm{M}$ \\
\hline 4 & $\begin{array}{l}\text { Determine } \\
\text { Interfaces Between } \\
\text { Concrete and } \\
\text { Other Materials }\end{array}$ & Medium & $\begin{array}{c}3 \mathrm{Years} \\
\$ 500 \mathrm{~K} / \mathrm{yr}\end{array}$ & $6 \mathrm{FTEs}$ & $\$ 1.5 \mathrm{M}$ \\
\hline 5 & $\begin{array}{l}\text { Acceptance } \\
\text { Criteria } \\
\text { Development }\end{array}$ & High & $\begin{array}{c}3 \mathrm{Years} \\
\$ 375 \mathrm{~K} / \mathrm{yr}\end{array}$ & $4.5 \mathrm{FTEs}$ & $\$ 1.2 \mathrm{M}$ \\
\hline 6 & $\begin{array}{l}\text { Automated } \\
\text { Scanning System } \\
\text { Development }\end{array}$ & Medium & $\begin{array}{c}2 \mathrm{Years} \\
\$ 250 \mathrm{~K} / \mathrm{yr}\end{array}$ & $1 \mathrm{FTE}$ & $\$ 500 \mathrm{~K}$ \\
\hline
\end{tabular}

The minimum duration for each project is listed above assuming "full funding". Progress can be made with less annual funding by extending the period of performance. While it is desirable that the first five of these R\&D tasks be performed in parallel, funding levels may preclude simultaneous R\&D so these tasks will be ranked according to priority.

As shown in Appendix C, each of the three working groups identified the need for volumetric 
imaging so task \#2 is deemed to have the highest priority, as a picture is worth a thousand words. Volumetric imaging also received the most votes during the workshop voting phase. A close second is task $\# 1$, as samples are required to compare and validate any of the NDE concrete measurement techniques. Task \#1 should be able to leverage ongoing activities by other interested parties to minimize the cost of this activity.

The determination of the condition of the interface between concrete and other materials (task \#4) is challenging, yet an important measurement to the nuclear power industry, so it is ranked next. The next priority would be R\&D task \#5. This would be logical as modeling and validation will provide the metric measurements required to determine if a concrete structure is "good enough." This effort will provide the required accuracy and resolution for any of the NDE concrete measurements that are developed in tasks \#2 and \#4.

R\&D task \#3 is probably the most challenging of all the tasks since measuring the physical and chemical properties of the concrete as a function of depth is very difficult, but it would provide relevant structural integrity information.

Once the NDE concrete instrumentation has been developed, then automating the scanning process (task \#6) will be advantageous.

A Gantt chart illustrating the recommend "staging" of these tasks is shown in Figure 12.

\begin{tabular}{|c|c|c|c|c|c|c|c|c|c|c|c|c|c|c|c|c|c|c|c|c|c|c|c|c|c|c|}
\hline \multirow{2}{*}{10} & \multirow{2}{*}{ Stort } & \multirow{2}{*}{ Finish } & 2012 & \multicolumn{4}{|c|}{2013} & \multicolumn{4}{|c|}{2014} & \multicolumn{4}{|c|}{2015} & \multicolumn{4}{|c|}{2016} & \multicolumn{4}{|c|}{2017} & \multicolumn{3}{|c|}{2018} \\
\hline & & & $a d$ & $a t$ & a2 & as & $a s$ & $a t$ & a2 & 03 & ad & $\alpha t$ & a2 & a. & as & $\alpha 1$ & $a_{2}$ & as & $a t$ & $a t$ & a2 & as & ad & $a 1$ & $a_{2}$ & $a_{3}$ \\
\hline 1 & 10/1/2012 & 9/30/2013 & & & & & & & & & & & & & & & & & & & & & & & & \\
\hline 2 & 10/1/2012 & 9/30/2016 & & & & & & & & & & & & & & & & & & & & & & & & \\
\hline 3 & $10 / 1 / 2014$ & 9/28/2018 & & & & & & & & & & & & & & & & & & & & & & & & \\
\hline 4 & $10 / 1 / 2013$ & 9/30/2016 & & & & & & & & & & & & & & & & & & & & & & & & \\
\hline 5 & $10 / 1 / 2013$ & 9/29/2016 & & & & & & & & & & & & & & & & & & & & & & & & \\
\hline 6 & $10 / 3 / 2016$ & $9 / 28 / 2018$ & & & & & & & & & & & & & & & & & & & & & & & & \\
\hline
\end{tabular}

Figure 12. Gantt Chart for the Concrete NDE tasks. 


\section{REFERENCES}

[1] L. J. Bond, "Old Reactors, New Tricks," IEEE Spectrum, vol. 49, no. 8, pp. 30-35, August 2012.

[2] "Light Water Reactor Sustainability Program Integrated Program Plan Revision 0," January 2012.

[3] International Atomic Energy Agency, "Guidebook on non-destructive testing of concrete structures," IAEA-TCS-17; Training Course Series No. 17, 2002.

[4] D. L. Fillmore, "Literature Review of the Effects of Radiation and Temperature on the Aging of Concrete," September 2004.

[5] International Atomic Energy Agency, "Assessment and management of ageing of major nuclear plant compnonents important to safety: Concrete containment buildings," IAEA-TECDOC1025, 1998.

[6] G. Zacher, C. Kohl, J. Wostmann, and C. Maierhofer, "Evaluation of radar and complementary echo methods for NDT of concrete elements," Journal of Nondestructive Evaluation, vol. 27, pp. 47-57, 2008.

[7] R. Arndt, "Electromagnetic methods for RC inspection," in Short Course on NDE for the Infrastructure, 2011.

[8] J. Cu, D. Huston, and R. Arndt, "Monitoring of reinforced concrete corrosion and deterioration by periodic multisensory non-destructive evaluation," The Review of Progress in Quantitative Nondestructive Evaluation, San Diego, CA, 2010.

[9] United States Environmental Protection Agency, "Environmental Geophysics: Ground Penetrating Radar," 7 November 2011. [Online]. Available: http://www.epa.gov/esd/cmb/ GeophysicsWebsite/pages/reference/methods/Surface_Geophysical_Methods/ Electromagnetic_Methods/Ground-Penetrating_Radar.htm. [Accessed 6 September 2012].

[10] J. Popovics, "Ultrasonic and X-ray imaging," in Short Course on NDE for the Infrastructure, 2011.

[11] D. Schurr, "Monitoring damage in concrete using diffuse ultrasonic coda wave interferometry," Georgia Institute of Technology, Atlanta, GA, 2010.

[12] M. Sherman, "NDE needs of buildings and structures," in Short Course on NDE for the Infrastructure, 2011.

[13] H. Wiggenhauser, "Advanced NDT methods for quality assurance of concrete structures," Non-Destructive Testinf in Civil Engineering (NDTCE'09), 2009.

[14] T. Schumacher, "Acoustic Emission Monitoring," in Short Course on NDE for the Infrastructure, 2011.

[15] J. Popovics, "NDE techniques for concrete and masonry structures," Progress in Structural Engineering and Materials, vol. 5, pp. 49-59, 2003.

[16] "Introducing the FHWA's NDE validation center," [Online]. Available: www.fhwa.dot.gov.

[17] K. Mayer, R. Marklein, K. J. Langenberg, T. Kreutter, "Three-dimensional imaging system based on Fourier transform sythetic aperture focusing technique," Ultrasonics, vol. 28, pp. 241-255, 1990.

[18] M. Schickert, M. Krause, W. Mueller, "Ultrasonic imaging of concrete elements using 
reconstruction by synthetic aperture focussing technique," Journal of Materials in Civil Engineering, vol. 15, no. 3, 2003.

[19] Florida Department of Transportation, "Validation of Nondestructive Testing Equipment for Concrete," Final Report BD545, 2010.

[20] D. Algernon, D. R. Hiltunen, C. X. Ferraro and C. . Ishee, "NDT Validation Facility at the Florida Department of Transportation," Review of progress in quantitative nondestructive evaluation, vol. 30A; 30B, no. AIP Conf. Proc., pp. 1448-1455, 2010.

[21] D.Algernon, D. R. Hiltunen, C. C. Ferraro, and C. A. Ishee, "Rebar Detection using Covermeter and Ultrasonic Pulse-Echo in combination with an automated scanning system.," Trasportation Research Record (TRR): Journal of the Transportation Research Board, Transportation Research Board of the National Academies, Washington, D.C., no. 2251, pp. 123-131, 2011.

[22] M. J. Sansalone, W. B. Streett, Impact-Echo - Nondestructive Evaluation for Concrete and Masonry, Ithaca: Bullbirer Press, 1997.

[23] H. Wiggenhauser, "Duct inspection using scanning impact-echo," in International Symposium Non-Destructive Testing in Civil Engineering (NDT-CE), Berlin, Germany, September 2003.

[24] J. Zhu, "Non-Contact NDT of Concrete Structures Using Air-Coupled Sensors," UrbanaChampaign, 2005.

[25] S.H. Lee, E. Fernandez-Gomex, J. Zhu, "Evaluating surface-breaking cracks in concrete using air-coupled sensors," ACI Materials Journal, 2011.

[26] J. Zhu, J. S. Popovics, "Air-Coupled Impact-Echo Imaging of Concrete Structures," in 6th International Symposium on NDT in Civil Engineering (NDT-CE), St. Louis, Missouri, August 2006.

[27] D.Algernon, H. Ernst, K. Dressler, "Assessment of Structural Concrete Components using Air-Coupled Impact-Echo," in Proceedings of the 9th International Concerence on NDE in Relation to Structural Integrity for Nuclear and Pressurised Components, Seattle, May 22-24, 2012.

[28] D. Naus, "Nuclear concrete structures," in Short course on NDE for the Infrastructure, 2011.

[29] D. Naus, "Primer on durability of nuclear power plant reinforced concrete structures - A review of pertinent factors," in NUREG/CR-6927, 2007.

[30] J. Sun, "Quantitative three-dimensional imaging by thermal tomography method," in The Review of Progress ion Quantitative Nondestructive Evaluation (QNDE), San Diego, CA, 2010.

[31] Nuclear Energy Agency, "Electrochemical techniques to detect corrosion in concrete structures in nuclear installations," NEA/CSNI/R(2002)21, 2002.

[32] D. Breysse, M. Soutsos, R. Felicette, M. Krause, J. Lataste, A. Moczko, "How to improve the quality of concrete assessment by combining several NDT measurements," NonDestructive Testing in Civil Engineering (NDTCE'09), 2009.

[33] O. Klinghoffer, A. Kristensen, O. Jovall, N. Ryden, "Condition assessment of concrete structures at nuclear power plants by state of the art non-destructive testing," in International Workshop on Ageing Management of Nuclear Power Plants and Waste Disposal Structures, Toronto, Canada, 2010. 
[34] K. Reichling, M. Raupach, H. Wiggenhauser, M. Stoppel, G. Dobmann, J. Kurz, "BETOSCAN - Robot controlled non-destructive diagnosis of reinforced concrete decks," in Non-Destructive Testing in Civil Engineering (NDTCE'09), Nantes, France, 2009.

[35] J. Zhu and J. S. Popovics, "Imaging Concrete Structures Using Air-Coupled Impace-Echo," Engineering Mechanics, no. 133, 628, 2007. 



\section{APPENDIX A. WORKSHOP ATTENDANCE LIST}

Table A-1. Concrete NDE Workshop Attendee List

\begin{tabular}{|l|l|}
\hline Name & Affiliation \\
\hline Sasan Bakhtiari & Argonne National Laboratory \\
\hline Leonard Bond & Iowa State University \\
\hline Cy Smith & Oak Ridge National Laboratory \\
\hline Dwight Clayton & Oak Ridge National Laboratory \\
\hline Kevin Simmons & Pacific Northwest National Laboratory \\
\hline Pradeep Ramuhalli & Pacific Northwest National Laboratory \\
\hline David Brenchley & Pacific Northwest National Laboratory \\
\hline Wes Hines & University of Tennessee, Knoxville \\
\hline Larry Jacobs & Georgia Tech \\
\hline John Lareau & WesDyne \\
\hline James Wall & Electric Power Research Institute \\
\hline John Lindberg & Electric Power Research Institute \\
\hline Maria Guimaraes Biagini & Electric Power Research Institute \\
\hline Yann LePape & Electricité de France (in residence at EPRI) \\
\hline John Burke & Nuclear Regulatory Commission \\
\hline Mita Sircar & Nuclear Regulatory Commission \\
\hline Tim Roney & Idaho National Laboratory \\
\hline Venu Varma & Oak Ridge National Laboratory \\
\hline Roger Kisner & Oak Ridge National Laboratory \\
\hline Daniel Algernon & Swiss Association for Technical Inspection \\
\hline John Popovics & University of Illinois \\
\hline John Cabage & University of Tennessee, Knoxville \\
\hline Thomas Rosseel & Oak Ridge National Laboratory \\
\hline Larry Yi-Lung Mo & University of Houston \\
\hline Jamie Coble & Pacific Northwest National Laboratory \\
\hline Blake Van Hoy & Oak Ridge National Laboratory \\
\hline Roberto Lenarduzzi & Oak Ridge National Laboratory \\
\hline Mike Hileman & Oak Ridge National Laboratory \\
\hline & \\
\hline
\end{tabular}





\title{
APPENDIX B. WORKSHOP AGENDA
}

\author{
Agenda \\ LWRS NDE Concrete Workshop \\ July 31, 2012
}

The purpose of this workshop is to develop content for the LWRS NDE R\&D roadmap. The focus will be on NDE techniques for detecting degradation in concrete.

\begin{tabular}{|c|c|}
\hline \multicolumn{2}{|l|}{ 7:30 AM - Registration } \\
\hline 8:00 AM - Welcome \& Workshop Overview & Dwight Clayton (ORNL) \\
\hline 8:10 AM - Introductions & David Brenchley (PNNL) \\
\hline $\begin{array}{l}\text { 8:30 AM - Concrete Degradation in Nuclear Generating } \\
\text { Stations }\end{array}$ & $\begin{array}{l}\text { Yann LePape } \\
\text { (EDF R\&D/EDF Inc.) } \\
\text { (In residence at EPRI, Charlotte) }\end{array}$ \\
\hline 9:00 AM - Promising NDE Technologies \& Methodologies & Clayton / Brenchley \\
\hline $\begin{array}{l}\text { 9:05 AM - NDE/DHM Technologies for Reinforced Concrete } \\
\text { Structures }\end{array}$ & $\begin{array}{l}\text { John Popovics } \\
\text { (University of Illinois) }\end{array}$ \\
\hline 9:40 AM - EPRI Research in NDE for Concrete & $\begin{array}{l}\text { John Lindberg (EPRI) and Maria } \\
\text { Guimaraes (EPRI) }\end{array}$ \\
\hline \multicolumn{2}{|l|}{ 10:15 AM - Break } \\
\hline 10:30 AM - Brainstorming Session & Brenchley \\
\hline $\begin{array}{l}\text { 11:15 AM - Define R\&D Actions to Address Gaps } \\
\text { (Working Groups) }\end{array}$ & Brenchley \\
\hline \multicolumn{2}{|l|}{ Working LUNCH } \\
\hline 1:30 PM - Group Reports \& Discussion & Brenchley \\
\hline 2:30 PM - Prioritize R\&D Actions & Brenchley \\
\hline \multicolumn{2}{|l|}{ 3:30 PM - Break } \\
\hline 4:00 PM - What Next and Assignments & Clayton \\
\hline 4:30 PM - Closeout & Brenchley \\
\hline 5:00 PM - Thank You \& Adjourn & Clayton \\
\hline
\end{tabular}





\section{APPENDIX C. WORKSHOP WORKING GROUPS}

\section{C-1 WORKING GROUP INTRODUCTION}

This workshop was held at Oak Ridge National Laboratory on Tuesday, July 31, 2012. David Brenchley presided over the management of the workshop working together with Dwight Clayton. The workshop began with a "check-in" session whereby each attendee was asked to submit a short list of the topics of their main interest.

Next, presentations were made by Yann Lepape on Concrete Degradation in Nuclear Generating Stations, John Popovics on NDE/DHM Technologies for Reinforced Concrete Structures, and John Lindberg and Maria Guimaraes on EPRI Reseach in NDE for Concrete. Following a brainstorming and discussion session, the 28 participants were divided into three groups to assemble in different breakout rooms. Table 1.1 shows the three groups and their respective members:

Table C-1. Working Group Members

\begin{tabular}{|c|c|c|}
\hline Group 1 & Group 2 & Group 3 \\
\hline $\begin{array}{ll}- & \begin{array}{l}\text { Dwight Clayton } \\
\text { (Lead) ORNL }\end{array} \\
- & \text { Larry Jacobs } \\
\text { Georgia Tech } \\
-\quad & \text { Roger Kisner } \\
\text { ORNL } & \text { Leonard Bond } \\
- & \text { Iowa State University } \\
-\quad & \text { John Popovics } \\
-\quad \text { University of Illinois } \\
-\quad \text { Mita Sircar } \\
\text { NRC } \\
\text { Yann LePape } \\
\text { Electricite de France (in } \\
\text { residence at EPRI) } \\
\text { Maria Guimaraes- } \\
\text { Biagini } \\
\text { EPRI }\end{array}$ & $\begin{array}{ll}- & \begin{array}{l}\text { Pradeep Ramuhalli } \\
\text { (Lead) PNNL }\end{array} \\
- & \text { Tom Rosseel } \\
& \text { ORNL } \\
-\quad & \text { Blake Van Hoy } \\
& \text { ORNL } \\
-\quad & \text { Susan Bakhtiari } \\
& \text { ANL } \\
-\quad & \text { James Wall } \\
\text { - } & \text { EPRI } \\
\text { John Cabbage } \\
\text { University of Tennessee, } \\
\text { Knoxville } \\
-\quad \text { Tim Roney } \\
\text { INL } \\
\text { Mike Hileman } \\
\text { ORNL }\end{array}$ & $\begin{array}{ll}- & \text { Cy Smith (Lead) } \\
- & \text { ORNL } \\
-\quad & \text { John Lindberg } \\
& \text { EPRI } \\
-\quad & \text { Daniel Algernon } \\
& \text { Swiss Association for } \\
& \text { Technical Inspection } \\
-\quad & \text { John Lareau } \\
& \text { WesDyne } \\
-\quad & \text { Roberto Lenarduzzi } \\
- & \text { ORNL } \\
- & \text { Jamie Coble } \\
& \text { PNNL } \\
-\quad \text { Larry Yi-Lung Mo } \\
\text { University of Houston } \\
\text { John Burke } \\
\text { NRC }\end{array}$ \\
\hline
\end{tabular}




\section{C-2 CONCLUSION OF BREAKOUT SESSIONS}

The breakout sessions had about two hours to arrive at their proposals. Following are the main conclusions of work from each group.

\section{C-2.1 Group 1 (Head of the Group: Dwight Clayton)}

This group introduced six areas of important gaps and R\&D needs to fill these gaps. These areas are identified in the following tables.

Table C-2. Working Group \#1 R\&D Task \#1

\begin{tabular}{|l|l|}
\hline Measurements wanted: & Inspection through steel liners \\
\hline Current NDE Capability: & $\begin{array}{l}\text { Very limited - liner-concrete bonding Ultrasonic Array, Radiography (double } \\
\text { sided), backscatter radiography, impact echo, impulse response - rebar limits } \\
\text { depth below liner. Can only find large voids with low frequency Ultrasonic }\end{array}$ \\
\hline The GAP: & Very limited capability to inspect concrete through liners \\
\hline Research Objective: & $\begin{array}{l}\text { Provide capability to inspect concrete through steel liners into concrete: near } \\
\text { interface inspection }\end{array}$ \\
\hline Scope of Work: & $\begin{array}{l}\text { Develop calibrated samples. Proof-of-concept }- \text { detect } 100 \mathrm{~cm}^{2}(?) \text { defect } 15 \\
\text { cm into mass of concrete. Develop and evaluate technology. Technology } \\
\text { demonstration (lab) }\end{array}$ \\
\hline Expected Outcomes: & New measurement capability \\
\hline Schedule: & 3 years \\
\hline Budget: & $\begin{array}{l}\text { FTE 2 per year } \\
\text { Samples and equipment (\$100k per year) } \\
\$ 600 k \text { per year }=\$ 1.8 \mathrm{M}\end{array}$ \\
\hline Ranking: & Medium \\
\hline
\end{tabular}


Table C-3. Working Group \#1 R\&D Task \#2

\begin{tabular}{|c|c|}
\hline Measurements wanted: & $\begin{array}{l}\text { Inspection of embedded steel through concrete: } \\
\text { (i) Embedded sheet } \\
\text { (ii) Embedded rebar/tendon - for corrosion }\end{array}$ \\
\hline Current NDE Capability: & Liners can be measured using thickness gauge - guided waves some capability \\
\hline The GAP: & $\begin{array}{l}\text { Methods that apply to detect buried steel (section loss) - active corrosion rate } \\
\text { determination }\end{array}$ \\
\hline Research Objective: & $\begin{array}{l}\text { Develop methods that characterize degradation of buried steel (section loss) - } \\
\text { and active corrosion rate determination }\end{array}$ \\
\hline Scope of Work: & $\begin{array}{l}\text { Select plate liners buried in concrete for proof of concept. Prepare samples - } \\
\text { visible and buried sections of structure (wall and in base mat). Develop and } \\
\text { evaluate technology for inspect for corrosion. Performance demonstration - } \\
\text { target } 10 \% \text { loss in thickness }\end{array}$ \\
\hline Expected Outcomes: & New inspection technology \\
\hline Schedule: & 3 Years \\
\hline Budget: & $\begin{array}{l}2 \text { FTE }(\$ 500 \text { k per year }) \\
\text { Calibrated Samples }(\$ 250 \mathrm{~K}) \\
\text { Total: } \$ 1.75 \mathrm{M}\end{array}$ \\
\hline Ranking: & Medium \\
\hline
\end{tabular}


Table C-4. Working Group \#1 R\&D Task \#3

\begin{tabular}{|c|c|}
\hline Measurements wanted: & Inspection of buried rebar for corrosion (multi-layers) \\
\hline Current NDE Capability: & $\begin{array}{l}1^{\text {st }} \text { layer electro-mechanical or thermal + electro-chemical. Impact echo for } \\
\text { delamination. Phased array for delamination. }\end{array}$ \\
\hline The GAP: & $\begin{array}{l}\text { No methods that can size section loss and provide degradation rate/metal loss - } \\
\text { particularly layer }\end{array}$ \\
\hline Research Objective: & $\begin{array}{l}\text { Develop methods that can size section loss and provide degradation rate/metal } \\
\text { loss. Need to minimize ambiguity - i.e. buried layer imaging. }\end{array}$ \\
\hline Scope of Work: & $\begin{array}{l}\text { Samples of rebar in concrete. Develop and evaluate technology for inspecting } \\
\text { for corrosion. Performance demonstration - target } 10 \% \text { loss in cross section }\end{array}$ \\
\hline Expected Outcomes: & New inspection technology \\
\hline Schedule: & 3 years \\
\hline Budget: & $\begin{array}{l}3 \text { FTE }(\$ 750 \mathrm{k} \text { per year }) \\
\text { Calibrated samples }(\$ 75 \mathrm{k}) \\
\text { Equipment } \$ 150 \mathrm{k} \\
\text { Total: } \$ 2.5 \mathrm{M}\end{array}$ \\
\hline Ranking: & High \\
\hline
\end{tabular}


Table C-5. Working Group \#1 R\&D Task \#4

\begin{tabular}{|c|c|}
\hline Measurements wanted: & $\begin{array}{l}\text { Volume imaging of thick sections highly reinforced concrete with single sided } \\
\text { access. }\end{array}$ \\
\hline Current NDE Capability: & $\begin{array}{l}\text { Multi-element low-frequency ultrasonic array. Cannot see very deep - looks } \\
\text { little beyond } 1^{\text {st }} \text { layer of rebar. }\end{array}$ \\
\hline The GAP: & $\begin{array}{l}\text { Need ability to look at multi-layer highly reinforced structure --- void - rebar } \\
\text { discrimination }\end{array}$ \\
\hline Research Objective: & $\begin{array}{l}\text { Provide ability to look into multi-layer highly reinforced structure and provide } \\
\text { void - rebar discrimination at depth }\end{array}$ \\
\hline Scope of Work: & $\begin{array}{l}\text { Provide calibrated samples. Investigate EM, UT, and radiographic approaches } \\
\text { (back-scatter neutrons and gamma). Look for insights from bore-hole } \\
\text { characterization methods. Investigate signal processing options. Provide proof- } \\
\text { of-concept system }\end{array}$ \\
\hline Expected Outcomes: & New instrumentation and integration of techniques \\
\hline Schedule: & 4 years \\
\hline Budget: & $\begin{array}{l}3 \text { FTE }(\$ 750 \mathrm{k} \text { per year })=\$ 3 \mathrm{M} \\
\text { Calibrated samples }(\$ 100 \mathrm{k}) \\
\text { Equipment } \$ 400 \mathrm{k} \\
\text { Total: } \$ 3.5 \mathrm{M}\end{array}$ \\
\hline Ranking: & Ultra High (11 on 10 point scale) \\
\hline
\end{tabular}


Table C-6. Working Group \#1 R\&D Task \#5

\begin{tabular}{|l|l|}
\hline Measurements wanted: & Acceptance criteria and Probabilities of Detection (POD) \\
\hline Current NDE Capability: & $\begin{array}{l}\text { Limited - different groups do parts of the problem. No integrated approach and } \\
\text { validation of performance for concrete structures }\end{array}$ \\
\hline The GAP: & $\begin{array}{l}\text { Application of simulation and POD determination to concrete inspection: } \\
\text { critical defect size, detection }\end{array}$ \\
\hline Research Objective: & Provide understanding of POD and quantification of performance \\
\hline Scope of Work: & $\begin{array}{l}\text { Modeling responses for critical defects in concrete - to study to \& quantify } \\
\text { POD applied to concrete structures (validated using experimental data from } \\
\text { other LWRS projects) [leverage current modeling approaches i.e., CIVA, etc.] }\end{array}$ \\
\hline Expected Outcomes: & Quantification of performance and acceptance criteria. \\
\hline Schedule: & 3 years \\
\hline Budget: & $\begin{array}{l}1.5 \text { FTE (\$375k/year) } \\
\text { Equipment: Software and Good Workstation }\end{array}$ \\
\hline Ranking: & High \\
\hline
\end{tabular}

Table C-7. Working Group \#1 R\&D Task \#6

\begin{tabular}{|c|c|}
\hline Measurements wanted: & Deployment of NDE \\
\hline Current NDE Capability: & $\begin{array}{l}\text { Much is still manual. Automation in laboratory and other fields like aero-space } \\
\text { (AF MAUS) }\end{array}$ \\
\hline The GAP: & Application to large area concrete surfaces - vertical and curved areas \\
\hline Research Objective: & $\begin{array}{l}\text { Provide flexible platform for large area concrete surfaces inspection including } \\
\text { vertical and curved areas }\end{array}$ \\
\hline Scope of Work: & $\begin{array}{l}\text { Develop flexible platform for large area concrete surfaces inspection including } \\
\text { vertical and curved areas }\end{array}$ \\
\hline Expected Outcomes: & Platform for NDE technologies \\
\hline Schedule: & 2 years \\
\hline Budget: & 1 FTE (levering EPRI efforts) \\
\hline Ranking: & Medium \\
\hline
\end{tabular}




\section{C-2.2 Group 2 (Head of the Group: Pradeep Ramuhalli)}

This group introduced four areas of important gaps and R\&D needs to fill these gaps. These areas are identified in the tables that follow.

Table C-8. Working Group \#2 R\&D Task \#1

\begin{tabular}{|c|c|}
\hline Measurements wanted: & $\begin{array}{l}\text { Physical properties (young's modulus, strength, moment of inertia, porosity, } \\
\text { permeability, etc.) }\end{array}$ \\
\hline Current NDE Capability: & $\begin{array}{l}\text { Destructive methods available (core testing/pullout testing). Laboratory NDE } \\
\text { (mainly UT) methods have been reported. }\end{array}$ \\
\hline The GAP: & $\begin{array}{l}\text { - No in-situ NDE methods to directly measure strength and many other } \\
\text { physical properties } \\
\text { - } \quad \text { Penetration depth, shadowing } \\
\text { - } \quad \text { Distributed vs local - length scales }\end{array}$ \\
\hline Research Objective: & $\begin{array}{l}\text { Develop volumetric NDE methods to estimate physical properties in-situ, as a } \\
\text { function of penetration depth }\end{array}$ \\
\hline Scope of Work: & 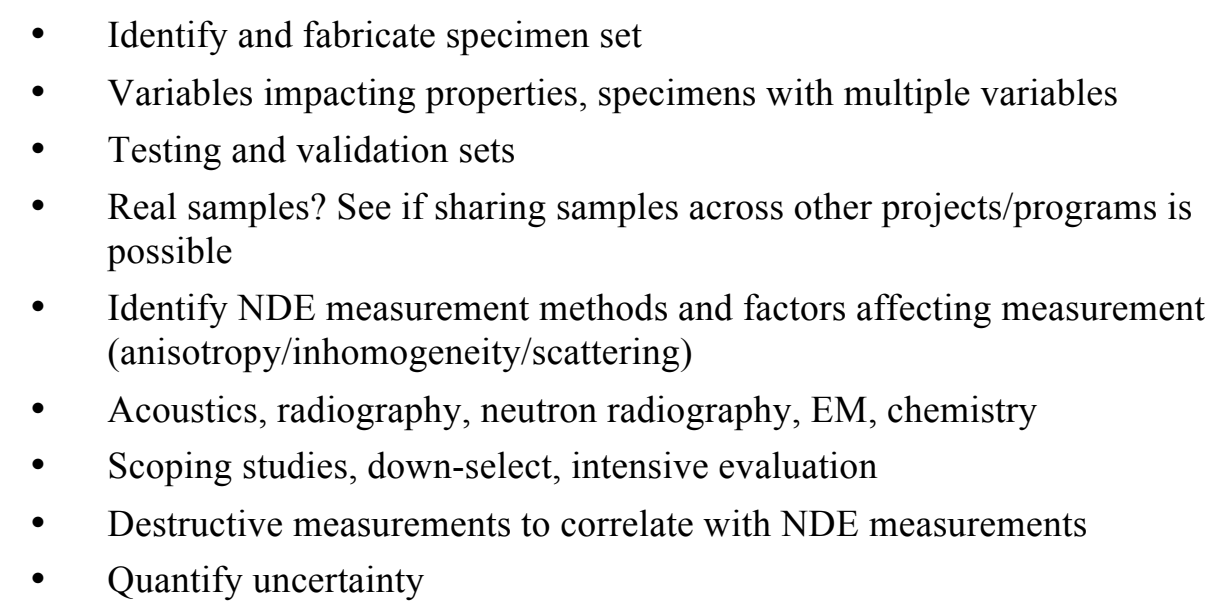 \\
\hline Expected Outcomes: & Quantitative NDE methods for inferring physical properties \\
\hline Schedule: & 4 years (with off-ramps after 1 or 2 years) \\
\hline Budget: & 4 FTEs/year, \$1 M per year, equipment - \$125K-150K/year; Total \$4.6 M \\
\hline Ranking: & High \\
\hline
\end{tabular}


Table C-9. Working Group \#2 R\&D Task \#2

\begin{tabular}{|l|l|}
\hline Measurements wanted: & Corrosion of internal steel elements (tendons and rebar) and liners \\
\hline Current NDE Capability: & $\begin{array}{l}\text { Acoustic imaging may be possible (based on some published reports). Half-cell } \\
\text { potential, microwave holography, radiography - all have shown potential in lab } \\
\text { studies }\end{array}$ \\
\hline The GAP: & Quantitative technique demonstration \\
\hline Research Objective: & $\begin{array}{l}\text { Quantitative evaluation of NDE methods for corrosion in internal steel } \\
\text { elements/liners }\end{array}$ \\
\hline Scope of Work: & $\begin{array}{l}\text { Define corrosion standards (possibly using existing metrics); Prepare specimen } \\
\text { set; conduct lab-scale studies to determine sensitivity and repeatability; } \\
\text { Document results. }\end{array}$ \\
\hline Expected Outcomes: & $\begin{array}{l}\text { Quantitative assessment of NDE methods for corrosion in internal steel } \\
\text { elements/liners }\end{array}$ \\
\hline Schedule: & $3-4$ years \\
\hline Budget: & $\begin{array}{l}2 \text { FTEs/year + equipment (\$100K); \$600 K/year } \\
\text { Specimen budget is not included. }\end{array}$ \\
\hline Ranking: & Medium \\
\hline
\end{tabular}

Table C-10. Working Group \#2 R\&D Task \#3

\begin{tabular}{|c|c|}
\hline Measurements wanted: & Radiation and thermal damage in concrete \\
\hline Current NDE Capability: & None in concrete. \\
\hline The GAP: & NDE methods \\
\hline Research Objective: & Develop NDE techniques to characterize radiation and thermal damage \\
\hline Scope of Work: & $\begin{array}{l}\text { Research contingent on results from joint DOE/EPRI concrete radiation } \\
\text { materials aging project } \\
\text { Samples - testing - models - leverage work from materials aging project. } \\
\text { Measurements on core samples from materials project? What measurements to } \\
\text { make? }\end{array}$ \\
\hline Expected Outcomes: & $\begin{array}{l}\text { Correlation between NDE and materials project outcomes based on laboratory- } \\
\text { scale measurements }\end{array}$ \\
\hline Schedule: & Delay until EPRI/DOE project progresses further (1-2 years?) \\
\hline Budget: & 1-2 FTEs (at least) + equipment costs \\
\hline Ranking: & $\begin{array}{l}\text { TBD, based on outcome of materials project (not clear to WG if there is a } \\
\text { significant problem due to radiation damage in concrete) }\end{array}$ \\
\hline
\end{tabular}


Table C-11. Working Group \#2 R\&D Task \#4

\begin{tabular}{|l|l|}
\hline Measurements wanted: & $\begin{array}{l}\text { Alkali-Silica reaction (ASR) damage in concrete as function of penetration } \\
\text { depth. Impacts compressive strength }\end{array}$ \\
\hline Current NDE Capability: & Current NDE Capability: nonlinear UT (lab-scale), visual. \\
\hline The GAP: & $\begin{array}{l}\text { No method to correlate evidence of external ASR damage with internal damage } \\
\text { and its effect on structural integrity }\end{array}$ \\
\hline Research Objective: & $\begin{array}{l}\text { Develop NDE methods to identify and quantify ASR damage in-situ, as a } \\
\text { function of depth }\end{array}$ \\
\hline Scope of Work: & $\begin{array}{l}\text { Accelerated ASR damage samples - run tests (different technologies) - } \\
\text { correlate with truth info (chemistry). Are there NDE methods (such as } \\
\text { spectroscopic measurements) that might give direct evidence of ASR? Depth of } \\
\text { penetration of ASR. }\end{array}$ \\
\hline Expected Outcomes: & NDE method for ASR damage as a function of depth \\
\hline Schedule: & 3-4 years \\
\hline Budget: & 2 FTE/year + equipment (?) and sample prep (\$75K-100K) \\
\hline Ranking: & Medium to High \\
\hline
\end{tabular}




\section{C-2.3 Group 3 (Head of the Group: Cy Smith)}

This group introduced five areas of important gaps and $R \& D$ needs to fill these gaps. These areas are summarized in the following tables.

Table C-12. Working Group \#3 R\&D Task \#1

\begin{tabular}{|l|l|}
\hline \multicolumn{2}{|l|}{} \\
\hline Measurements wanted: & $\begin{array}{l}\text { In containment with high temperature and high rad or spent fuel pool with } \\
\text { under water capability }\end{array}$ \\
\hline Current NDE Capability: & No current capability \\
\hline The GAP: & $\begin{array}{l}\text { Needs to be a robotic system that needs to carry some type of NDE technique. } \\
\text { Also needs to be rad hard or water submersible. }\end{array}$ \\
\hline Research Objective: & \\
\hline Scope of Work: & \\
\hline Expected Outcomes: & \\
\hline Schedule: & \\
\hline Budget: & \\
\hline Ranking: & Low priority (defer until NDE techniques are mature) \\
\hline
\end{tabular}


Table C-13. Working Group \#3 R\&D Task \#2

\begin{tabular}{|c|c|}
\hline \multirow{5}{*}{ Measurements wanted: } & Detection of property changes over time. \\
\hline & Young's Modulus \\
\hline & Density \\
\hline & Poisson's ratio \\
\hline & Strength \\
\hline Current NDE Capability: & $\begin{array}{l}\text { Nothing commercially available. In the laboratory we can make shear and P } \\
\text { wave velocity measurements that can determine the elastic parameters. No } \\
\text { current capability for strength }\end{array}$ \\
\hline The GAP: & $\begin{array}{l}\text { The gap is in shear and } \mathrm{p} \text { wave velocity measurements need to be developed, } \\
\text { validated and commercialized for the elastic properties and a new technique is } \\
\text { needed to measure strength. }\end{array}$ \\
\hline Research Objective: & $\begin{array}{l}\text { Validate how NDE techniques correlate to the elastic properties and develop a } \\
\text { technique for inferring or directly measuring strength }\end{array}$ \\
\hline Scope of Work: & Correlate the destructive testing with the NDE techniques \\
\hline Expected Outcomes: & Field deployable methods to characterize the strength and elastic properties. \\
\hline \multicolumn{2}{|l|}{ Schedule: } \\
\hline \multicolumn{2}{|l|}{ Budget: } \\
\hline Ranking: & High (very fundamental) \\
\hline
\end{tabular}


Table C-14. Working Group \#3 R\&D Task \#3

\begin{tabular}{|l|l|}
\hline Measurements wanted: & Indications of chemical attack \\
\hline Current NDE Capability: & Visual or none \\
\hline The GAP: & What properties change in concrete relative to chemical changes/attacks \\
\hline Research Objective: & $\begin{array}{l}\text { Identify the chemical attack mechanism and identify how they change the } \\
\text { material properties that can be measured NDE. }\end{array}$ \\
\hline Scope of Work: & $\begin{array}{l}\text { Roadmap to direct NDE development for detecting material properties changes } \\
\text { related to chemical attack }\end{array}$ \\
\hline Expected Outcomes: & \\
\hline Schedule: & High (Fundamental Research) \\
\hline Budget: & \\
\hline Ranking: &
\end{tabular}

Table C-15. Working Group \#3 R\&D Task \#4

\begin{tabular}{|l|l|}
\hline Measurements wanted: & $\begin{array}{l}\text { Volumetric image of the entire structure where the important features are } \\
\text { identifiable. Like an MRI/Cat-scan. }\end{array}$ \\
\hline Current NDE Capability: & None \\
\hline The GAP: & $\begin{array}{l}\text { Develop an algorithm to combine technology and perform data fusion on NDE } \\
\text { measurements. }\end{array}$ \\
\hline Research Objective: & $\begin{array}{l}\text { Combine data from different NDE techniques for developing a map of the } \\
\text { overall global volumetric image based on specific detail or property }\end{array}$ \\
\hline Scope of Work: & This would tie into the measurements of \#2 and \#3 to combine the entire image. \\
\hline Expected Outcomes: & $\begin{array}{l}\text { Develop a GIS type view where you can apply different layers for properties or } \\
\text { detail. }\end{array}$ \\
\hline Schedule: & \\
\hline Budget: & High \\
\hline Ranking: &
\end{tabular}


Table C-16. Working Group \#3 R\&D Task \#5

\begin{tabular}{|l|l|}
\hline Measurements wanted: & Retrofitted sensors for measuring changes in stress and strain \\
\hline Current NDE Capability: & $\begin{array}{l}\text { Fiber optic sensors for stress and strain, resistivity for chemical } \\
\text { potential(corrosion) }\end{array}$ \\
\hline The GAP: & Chemical sensors for leaching, how to retrofit use of these sensors \\
\hline Research Objective: & Identify sensors that can be embedded into the structure for retrofitting \\
\hline Scope of Work: & $\begin{array}{l}\text { Evaluate different sensors for application specific measurement. Evaluate data } \\
\text { form tension cables for inferring over all global structural integrity }\end{array}$ \\
\hline Expected Outcomes: & Sensors embedded during re-pours after opening the containment. \\
\hline Schedule: & \\
\hline Budget: & \\
\hline Ranking: & \\
\hline
\end{tabular}

\section{C-2.4 Prioritize Concrete NDE R\&D}

To evaluate and rank the proposals for NDE R\&D each participant was give six (6) total votes. He/she could cast no more than three votes for any one proposal. The following table shows the summary of votes cast. It was realized that some of the proposals developed by the three workings groups were very similar and could be combined.

Table C-17. Voting Results

\begin{tabular}{|c|l|c|}
\hline \multicolumn{1}{|c|}{ Proposal Description } & Results of Vote \\
\hline \multicolumn{1}{|c|}{ Group 1 } & \multicolumn{1}{|c|}{22} \\
\hline 1. & Volume imaging of thick sections highly reinforced concrete & 8 \\
\hline 2. & Inspection of embedded steel through concrete & 17 \\
\hline 3. & $\begin{array}{l}\text { Develop acceptance criteria and probabilities of detection (POD) } \\
\text { Inspection of buried rebar for corrosion (multi-layers) }\end{array}$ & 6 \\
\hline 4. & Inspection of concrete behind steel liners & 5 \\
\hline 5. & Characterize degradation of steel liners & 3 \\
\hline 6. & Deployment of NDE technologies & 26 \\
\hline \multicolumn{2}{|c|}{ Group 2 } & 1 \\
\hline 1. & Develop volumetric NDE methods to infer physical properties & 8 \\
\hline 2. & Corrosion of internal steel elements (tendons and rebar) and liners & 6 \\
\hline 3. & Radiation and thermal damage in concrete & \begin{tabular}{c}
$|c|$ \\
\hline 4.
\end{tabular} \\
\hline
\end{tabular}




\begin{tabular}{|c|l|c|}
\hline Item & \multicolumn{1}{|c|}{ Proposal Description } & Results of Vote \\
\hline \multicolumn{1}{|c|}{ Group 3 } \\
\hline 1. & $\begin{array}{l}|c| \\
\text { In containment with high temperature and high rad or spent fuel pool with } \\
\text { under water capability }\end{array}$ & 0 \\
\hline 2. & Detection of property changes over time & 16 \\
\hline 3. & Indications of chemical attack & 2 \\
\hline 4. & $\begin{array}{l}\text { Volumetric image of the entire structure where the important features are } \\
\text { identifiable }\end{array}$ & 13 \\
\hline 5. & Retrofitted sensors for measuring changes in stress and strain & 6 \\
\hline
\end{tabular}

The voting and the discussion that followed were used to identify higher priority NDE R\&D activities. The results from the workshop generated six key areas of importance:

1) Survey available samples

2) Technique(s) to perform volumetric imaging on thick reinforced concrete sections

3) Determine physical and chemical properties as a function of depth

4) Techniques to examine interfaces between concrete and other materials

5) Development of acceptance criteria - model and validation

6) Automated scanning system 